\title{
That Swimsuit Reveals You: Body Image and Bathing Suits of Florida Women
}

\author{
Anita Spring, $\mathrm{PhD}^{1}$ and Veronica McClain, $\mathrm{MPH}^{2}$ \\ ${ }^{1}$ Professor Emerita, Department of Anthropology, University of Florida \\ ${ }^{2}$ Data Scientist, Nielsen Media Research, University of Florida
}

\begin{abstract}
Swimsuits in the $21^{\text {st }}$ century are among the most revealing garments worn by American women publicly. History reveals that wearing swimsuits affected how American women objectified their bodies and defined attractiveness. For this study, ethnographic data were based on interviews (conducted during 2000-2009, 2013, and 2020) with swimwear industry personnel (company owners and representatives, designers, retailers, swimwear models, national/international staff at swimwear tradeshows, etc.) that were collected at major swimwear trade shows in Florida and company locations to inform and contextualize the research. Both quantitative and qualitative data were collected from 2000 to 2009, from purposive convenience-samples of women in Florida. The samples were aggregated to show similarities and differences between: (1) college students (Asian, Black, Latina, and White); (2) competitors (swim team, beauty-pageant contestants, and swimsuit models); and (3) adult women (Black, Latina, and White beachgoers, swimsuit shoppers, and aqua-aerobics class attendees).

The ethnographic qualitative data were collected from interviews at tradeshows and from sample subjects. The quantitative data were collected using standard anthropometric-measurement instruments (Body Mass Index (BMI), waist circumference, waist-hip ratio, and bust-waist ratio), and Figure-Rating and Body-Rating Scales using relevant protocols selected from the psychological and sociological literatures on body image. Data on preferred and actual body shapes and sizes were related to women subjects' swimsuit types and usages in particular situations. Findings partially matched and then expanded the literature of the time-period and showed that: (1) Women overestimated their body size-and-shape discrepancies from cultural ideals; (2) Fat-intolerant women were affected by the "thin-ideal", whereas fat-tolerant women were less affected; (3) some Black and Latina women lauded larger body size to mediate body dissatisfaction and enable swimsuit usage; (4) Asian women had conservative values rather than body-size limitations affecting swimsuit types and usage choices; (5) Competitors (who were thought to have little body-image dissatisfaction) nevertheless expressed body-dissatisfaction; and (6) unexpectedly, women of all ages and ethnic/racial groups expressed body-dissatisfaction throughout the lifespan, both in general, and when wearing swimsuits.
\end{abstract}

Key Words: Body Image, Swimsuits, Race \& Ethnicity, Florida Women, Anthropometry \& Quantitative Anthropology

\section{Introduction}

Since the 1920s in the United States, the "bathing suit" has been the most revealing garment that American women and men have worn in public. The swimwear industry has used the terms "swimsuits" and "swimwear," while the lay public used the term "bathing suits," implying water-related activities and sun-bathing. Women have been both dissatisfied and satisfied with their bodies while using these garments, due to the coverage provided by swimsuits and how they objectified their own bodies. 
This research utilized convenience samples of women to consider the relationships and interaction of women's measurements, with concepts of body image and body satisfaction. The focus on Florida related to the state's omnipresent "pool and beach culture" by residents and tourists. Before e-commerce, $27 \%$ of suits sold in the United States were sold in Florida, and swimwear companies in the state were many. Several major swimwear trade shows are held in Florida, and the ethnographic fieldwork (participant-observation and interviews) were carried out in Florida. ${ }^{1}$ The data were garnered from questionnaires of: University of Florida (UF) students, UF students on the Swim Team, and UF students competing in beauty pageants, as well as from swimwear models (often contestants), adult women on the beach and purchasing swimwear in department stores and boutiques, and women in aqua-aerobic classes at physical fitness facilities. Personnel from swimsuit companies (owners, trade representatives, retailers, etc. were interviewed at swimwear tradeshows and company headquarters. ${ }^{2}$ The researchers themselves were from the University of Florida.

Anthropology and other disciplines have used anthropometry of body measurements and ratios in cross-cultural research to differentiate body shapes and sizes that are linked to health parameters, beauty ideals, and ethnic-group membership. This study focused on measured body-mass-index (BMI), waist

\footnotetext{
1 The trade shows are "Miami Cruise" in July; "Surf Expo" in September and January, both in Orlando; "Early Cruise" in Miami in February; and the occasional Fort Lauderdale show.
}

2 This study is part of a larger anthropological study on women in Florida and their behavior and attitudes regarding swimsuits and women's bodies. The qualitative data will be discussed circumference (WC), waist-hip ratio (WHR), and waist-bust ratio (WBR). Ethnographic data included self-rating of oneself in a swimsuit, types of suits worn in various activities and situations, and women's "emotive" interactions with swimwear garments. ${ }^{2}$ Assessments of how women rated their bodies and how they felt when wearing swimsuits in various situations (such as on the beach, at home, in public, and in private), and in the company of others (friends and family) were ethnographically derived from observation and questionnaires. Also used were standard protocols from psychology and evolutionary psychology that studied subjects' ratings and evaluations of their body images using Figure Rating Scales, Body Catharsis Scales, and "My Body Right Now" designations.

There is a vast popular print literature (books, magazines, news articles, calendars, etc.) and media platforms (movies, TV, Internet/Websites, other video materials, social media, etc.) on women's (and more recently men's) body shapes and ideals. In addition, there is a vast scientific literature on body-image, self-esteem, and body dissatisfaction/satisfaction, research primarily carried out by psychologists and sociologists, but less so by anthropologists.

This article provides an anthropological perspective in terms of culturally configured samples, anthropometric variables, culturally configured findings, and cultural interpretations. Since the subject has not been widely addressed by

subsequently and consists of: (1) women's narratives relating to their use of swimsuits and comments about their own bodies; (2) interviews with industry personnel (company owners and employees, designers, sales representatives, retailers, and models); (3) participant observation at swimwear trade shows; and (4) archival research in libraries and museums. 
anthropologists, highlights of salient articles from the psychological and sociological literatures were also discussed. Reviewers also helped to identify some of the classic viewpoints. The anthropological view examines data that reveal the similarities and differences in terms of ethnicity and cultural variables. Anthropologists do not usually set up cultural experiments that measure subjects' discomforts versus their satisfactions with specific test conditions that then reveal their underlying disorders and fears. The psychology literature discussed below shows fascination with body self-objectification and wearing swimsuits as examples of stressful situations to measure body satisfaction (Fredrickson et al., 1998; Hebl et al., 2004; McKinley, 2006; Downs et al., 2006; Bovet 2018).

Health-care professionals take body dissatisfaction seriously because of the mental and physical health consequences, and body dissatisfaction is associated with depression pathologies and food-related disorders (anorexia and bulimia) (Barnett et al., 2001; Abrams \& Stormer, 2002; Warren et al., 2005). The body dissatisfaction literature variables show greater effects in women than men, and may be a product of family, peer, and media influences on women's body-image and self-esteem (Hausenblas et al., 2004). Media and social media were usually cited as the strongest factors in the preference of the "thin-ideal" for white, Latina, and Asian women, compared to socalled "problematic" larger bodies for some Black and Latina women (Allan et al., 1993; Bhuiyan, 2003; Bryd-Bredbenner \& Murray, 2003; Cash et al., 2004; Groesz et.al, 2002).

Currently, scholars have studied acceptance of larger bodies for women in general, as well as for Black and Latina women specifically (e.g., Hermanussen et al., 2019; Lieberman \& Probart, 1992; Lieberman, 2018, 2021). Many women believe that they are overweight even though they are considered normal or underweight (Davis et al., 1994; Allan et al., 1993; Crawford \& Campbell, 1999; Gapinski et al., 2004). The increased prevalence of dieting, as well as of other eating disorders reflect the high internalization, especially of the thin-ideal for some women. Parker et al. (1995) found that teenage girls in the United States used a more fixed image of beauty that was overly thin and were frustrated at their inability to have "perfect" bodies, which was seen as the way to achieve success in other parts of life, such as being popular or finding romance (Katznmarzky, 2001).

However, more recently, cultural rejection of this perspective has begun to show appreciation for larger-size bodies spurred on by media stars such as Lizzo, whose BMl is greater than 40 (Extreme Obese), and women in the past decade have been receiving messages to appreciate their bodies whatever their shapes and measurements (Lazuka, 2020; Lieberman, 2021; Sani et al., 2016; Swami et al., 2020). Concomitantly, in the past two decades. swimwear has been redesigned to accommodate greater diversity of body types, weights, and dimensions.

In this study, a series of hypotheses were developed after reviewing the literature on attractiveness and body shape/size; body dis/satisfaction and selfesteem; and body objectification. These dealt with: (1) anthropometric measurements and body image; (2) factors that influenced swimsuit usage; (3) race, ethnicity and cultural effects on body image and swimsuit usage; (4) rating scales on body objectification, dissatisfaction, and selfesteem; and (5) age factors affecting these variables. The subject of swimwear 
has been dynamic, and both localized and regionalized as changes in body/beauty preferences have changed and swimsuits following fashion trends changed through time. This research itself has evolved along with the swimwear industry over time and has allowed for studying changes in this dynamic industry and women's responses to them.

\section{Methods \\ Purposive Convenience Samples and Hypotheses}

This study used convenience samples of targeted populations based on geography, race/ethnicity, and swimwear usage. Twelve graduate and undergraduate students, who were predominantly anthropology majors attending the University of Florida (UF) and who interned with Professor Spring from 2000-2009, collected the data from students at UF, adult women at Florida beaches, and women shopping for swimsuits in North and South Florida. Additionally, a group termed herein Competitors included UF swimteam members, "Miss UF" beauty contestants, and swimwear models employed at two trade shows (Surf Expo in Orlando and Miami Swim) and at swimwear companies around the state. ${ }^{3}$. Pregnant and older women taking aqua-aerobic classes at physical-fitness facilities were also interviewed. The samples in Table 1 reflect Florida's diversity of swimwear users. The study targeted these convenience samples to understand the diversity of "ethnographic categories" of swimsuit users (1) White, Black, Latina, and Asian students; (2) Black and White women from North and South Florida interviewed on the

\footnotetext{
${ }^{3}$ Some body shapes match up well and form a client group for swimwear (swimsuit models, beauty and bikini contestants, and female swim team members). All subjects for the study lived in Florida a minimum of four years and most for much
}

beach; (3) Latina women on South Beach; (4) swimsuit shoppers (in department stores and boutiques) in South Florida and (5) White women doing aqua-aerobics. These categories were selected as comparable to the literature for this topic on White or non-Black/non-Latina (here called White), African-American or Black non-Latina (Rucker \& Cash, 1992; Allan et al., 1993; Harris, 1994; Parker et al., 1995; Molloy, 1998; Falconer \& Neville, 2000; Wildes et al., 2001; Bhuiyan et al., 2003); Asian American (e.g., Koff, 1998; Barnett et al., 2001); and Latina (Hebl et al., 2004; Warren et al., 2005).

Also, various previous studies considered older women, and showed that body image dissatisfaction had diminished with age (Tiggemann \& Lynch, 2001; Webster \& Tiggemann, 2003; McLaren \& Kuh, 2004). However, the research findings for this paper showed that women's dissatisfaction persisted throughout their lifespan.

\section{Convenience Samples, Age Range, and Ethnicities}

White, the largest category (49.7\%), includes 185 participants ranging from 1885 years. The group included students (early 20s), North and South Florida women (40-70 years), and aqua-aerobic women (30-70 years). Latina women included students (early 20s), South Florida women and department store' shoppers (40s-50s years), and Boutique Latinas (20s-40s years) who were surveyed at South Beach. Competitors (swim team, pageant contestants, and models) had the smallest age range (18-33 years).

longer. Some swim team members and swimwear models now living and working in Florida may have had less than four years $(48.4 \%$ and $28.6 \%$ respectively). 
Table 1. Samples, ages, and number of surveys.

\begin{tabular}{|c|c|c|c|c|c|}
\hline \multicolumn{2}{|c|}{ Sample } & $\begin{array}{c}\text { Age } \\
\text { Range }\end{array}$ & Mean Age & $\begin{array}{l}\text { Number of } \\
\text { Surveys }\end{array}$ & $\begin{array}{l}\text { Percent of } \\
\text { Sample }\end{array}$ \\
\hline White & $\begin{array}{l}\text { Students } \\
\text { N. FL Moms } \\
\text { S. FL Moms } \\
\text { Aqua Aerobics }\end{array}$ & $18-85$ & 36 & 185 & 49.7 \\
\hline Latina & $\begin{array}{c}\text { Students } \\
\text { S. FL Moms } \\
\text { Dept. Store } \\
\text { Fashion Boutique }\end{array}$ & $18-62$ & 29 & 35 & 9.4 \\
\hline Asian & $\begin{array}{c}\text { Students } \\
\text { Aqua Aerobics }\end{array}$ & $18-65$ & 22 & 30 & 8.1 \\
\hline Black & $\begin{array}{l}\text { African Amer. Stu- } \\
\text { dents } \\
\text { Caribbean Students } \\
\text { N. FL Moms }\end{array}$ & $18-62$ & 23 & 51 & 13.7 \\
\hline Competitors* & $\begin{array}{c}\text { SW Models } \\
\text { Swim Team } \\
\text { Beauty Contestants }\end{array}$ & $18-33$ & 21 & 71 & 19.1 \\
\hline Total & & $18-85$ & 29 & 372 & 100 \\
\hline
\end{tabular}

\section{Instruments}

For this study, the standard Anthropometric Measurements were chosen, that included Body Mass Index (BMI), Waist Circumference (WC), Waist-Hip Ratio (WHR), and Waist-Bust Ratio (WBR) developed by the National Institutes of Health. BMI is the main indicator of body fat or mass and is a ratio of an individual's height and weight. The ratio (weight in pounds/height in inches ${ }^{2} \times 703$ $=\mathrm{BMI}$ ) has been divided into six categories: Underweight (BMI >18.5); Normal: (18.5 to 24.9); Overweight (25.0 to 29.9); Obese Class I: (30.0 to 34.9); Obese Class II (35.0 to 39.9); and Extreme Obese $(<40.0)(\mathrm{NIH}, 2004)$. These categories have functioned for decades, but there have been some modifications since body weight and size in general has increased (Swami et al., 2020).

BMI, WHR, and WC functioned in this study as predictors of body composition and correlated with perceived and ideal body shapes. Low et al. (2003) found that women are more susceptible to body dissatisfaction when their BMI differed from cultural ideals. Bhuyian et al. (2003) used BMI to measure body size, finding that Black individuals perceived their weight as lower than their actual weight, while White individuals overestimated their perceived weight. Other authors confirmed that Black women preferred a larger body size and underestimated their

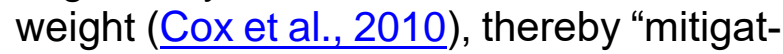
ing but not precluding body dissatisfaction" (McClure, 2012). 
BMl categories do not work as universal standards for all ethnic groups. Smaller and larger body sizes that are population-specific produce both similarities and differences from mainstream BMI designations. Stevens (2003) argued that cut-offs were arbitrary, and the smaller body size of many Asian groups (e.g., Malays, Chinese, Japanese, but not Mongolians and Northern Chinese) needed lower points to identify obesity, diabetes, and cardiovascular risks. Deurenberg et al. (2003) found that some cultural, "ethnic" and racial groups desired higher body weights for well-being and beauty. WC and WHR were found to be predictors of weight, attractiveness, and in some studies, of health outcomes. Many studies used images of women with diverse ratios to confirm the ratio of 0.67 as the evolutionary-based preferred body shape that also represented fecundity/fertility (Henss, 2000, Singh, 1993, 1994). Tovee (2012) argued that BMI only, and not "the other" anthropometric measurements (WHR, WC, WBR), provided benefits to health outcome. However, all these anthropometric measurements were useful for research on swimsuits and body image.

A significant influencer of rating oneself in a swimsuit can be found in the history of swimwear, starting with the Miss America Pageant (and by extension to beauty contests world-wide that had a "swimsuit category"4. The female body's "hour-glass shape", the "perfect" 0.67 (termed the "evolutionary ratio") persisted in various configurations through the centuries (Anderson-Fye, 2012; Downs et al.,

\footnotetext{
4 The Miss America Pageant ended its swimsuit competition in June 2018 and decided that (1) contestants would not be judged on physical appearance and (2) the event would become a competition not a pageant (en.m.wikipedia.org).
}

2006; Katzmarzyk \& Davis, 2001; Lassek \& Gaulin, 2016) but has been on display in swimsuit competitions including the Miss America Pageants from 1921 to 2018 (https://www.history.com/news/beauty-pageant-swimsuitcompetition-history; Bivans, 1991). The phrase "36-24-36" came to signify the meaning of this shape, which was epitomized in America by glamorous moviestars such as Betty Grable, Rita Hayward, Rosalind Russell, Marilyn Monroe and many others. ${ }^{5}$

However, with fitness and dietary changes beginning in the late 1960s/1970s in the U.S. and elsewhere, the "elongated" body shape began to replace the former worldwide ideal. Tall models with slender hips closer to waist size, and the bust either small or enhanced through medical procedures replaced the hour-glass shape. After the 1980 s, some younger women began preferring elongated rather than curvaceous figures, and by the 1990s, a third of Singh's (1995) sample preferred this shape. As a result, WHRs for contemporary tall ultra-slim runway models and beauty contestants approached 0.84 , which previously was associated with obese bodies (in which women's top, midsection, and thighs measured the same).

\section{Women's Self-evaluation Versus "the Male Gaze"}

This paper focuses on women's self-evaluation of their bodies (in general and in wearing swimsuits). To contextualize these aspects within evolutionary theories, WHR in relation to women's

\footnotetext{
${ }^{5}$ For a list see: https://glamamore.com/2013/08/sizing-up-oldhollywoodheights-weights.html?m=1).
} 
fecundity was examined. Discounting the "36-24-36" that was based on attractiveness in swimsuits and not on fertility, Bovet (2019) analyzed 104 papers from 1993 to 2007 that addressed men's preferences for women's shape using WHR, women's increased breast size (at puberty and menarche), and women's increased waist size (due to pregnancy) thereby signaling female fecundity, in this case, to men. Some studies showed that lower WHR signaled youthfulness. Bovet concluded that WHR could be linked to fecundity, but also linked to the availability of "reproductive fat" (abdominal fat helpful in pregnancy for fetal and infant brain development). Conclusions about males choosing females for reproductive success showed the consequences for reproductive success of mating with women with low WHRs, a cue for general health, but that a wide pelvis (for childbirth) might be more important.

Findings also showed that women with high WHRs had more chronic stress (ibid. 10) perhaps due to "the competition for a mate, not for competition for resources" (ibid. 11). Another part of the discussion ("Cue of Sexy Daughters") was that WHR was heritable, and that offspring with lower WHRs were more feminine and attractive to men. Research on men's preferences for women's WHR has been taken to task because of "unsound theoretical foundations" that lead to "imperfect predictions" (ibid). ${ }^{6}$

Bovet et al. (2018) found men judged women's facial attractiveness as more important than WHR in general. Also women with latter expected age at menopause (using mothers age at menopause as proxies) were "judged more attractive

\footnotetext{
${ }^{6}$ It should also be noted that this research initially included several convenience samples of men (UF students, men on Miami, South Beach, and on North Florida beaches) and their relationship

to swimwear but did not study men's evaluation of women's bodies in terms of WHR or their swimwear.

than those of women with an earlier expected age of menopause". Some studies (e.g., Lassek \& Gauluin, 2016, 2018) addressed low WHRs and BMIs, separated from other variables. The interesting analysis and sexist title, "What Makes Jessica Rabbit Sexy? Contrasting Roles of Waist and Hip Size," had three discrete samples: college women, Playboy playmates, and imaginary "cartoon and video-game" women (Lassek \& Gauluin, 2016). The major finding: that waist size was "the key determinant" of female body attractiveness accounting for the relationship of both BMI and WHR. The strongest predictors showed the samples of college women's small waists, Playboy playmates smaller waists and WHRs, and imaginary women still smaller waists. Hip sizes could be larger and confer attractiveness in all samples because of links to fecundity. Ironically, neither BMI nor WHR might hinder parturition, as much as small waists. The Lassek \& Gauluin (2018) article corroborated this finding: for American women, lower BMls produced fewer live births.

Many studies on objectification theory could be related to this paper's research on how objectification reduced women's bodies to physical appearance and treated girls and women's bodies as sexualized parts separated from their personhoods. However, the end results of "the male gaze" and the "female-self "gaze" on their own bodies has lead girls and women to assess themselves constantly to see if they meet 'cultural standards of attractiveness' and to internalize constant concern about their appearance. Roberts et al. (2018) diagrammed the process. Girls and women became their own 
first surveyors and internalized and became to be preoccupied with the appearance-dominant perspective of themselves, essentially, they "sexually objectified themselves" (ibid.249),

\section{Swimsuits and Body Objectification}

Many studies have investigated "physical body review" and its internalization of the objectifying "gaze". The theory also "holds the promise of emancipating girls and women from the mental and physical health risks that stem from this in quality" (ibid. 251). The results showed that women become "their own first surveyors self-objectifying as a way of anticipating rewards and punishments likely to come from "American culture" that valued their physical appearance above all (ibid.252). Calogero (2004:249) argued that "the two commonly studied features of self-objectification in the psychological literature were centrality of appearance to self-concept (a matter of seeing) and the habitual monitoring of appearance in anticipation of being looked at by others (a matter of doing)".

Additionally, body image, a complicated, many-sided subject with perceptual, affective, and cognitive aspects, (Thompson, 1996) could be changeable and situational, such as age and weight changes that could be triggered by overeating and lack of activity (Tiggemann, 2000), or issues could be triggered by self-objectification (Fredrickson et al., 1998; Weaver and Byers, 2006). Fredrickson et al.'s (1998) famous study considered women's relationships to swimsuits as the proxy situation for attractiveness and self-worth evoking negative aspects of body image and self-esteem. They posited that "in American culture, girls and women...tend to measure their self-worth by evaluating their physical appearance against our culture's sexually objectifying and unrealistic standards of beauty" (ibid.269). They gave White women and men swimsuit and sweater "conditions" to test how they objectified their bodies, and then asked subjects to answer mathematics questions. Women were more self-conscious, had greater body shame, lower self-esteem, and decreased mathematics performance while wearing swimsuits. Men's math performance was not affected by wearing swimsuits and they did not exhibit body shame or lower esteem.

Hebl et al. (2004) criticized Fredrickson et al. noting that the women students were asked to wear tight-fitting, clinging 1-piece suits, while their male counterparts were given swim trunks. They also noted that only White students were considered. Hence, these researchers repeated the study by sampling 96 Black, 88 Latina, 89 Asian, and 130 White students (56\% women and $44 \%$ men). They found that "African American women reported feeling less guilty and more accepting of their body size" and did not stigmatize obese people as much as Whites, while Asians and Latinas were more likely to "endorse mainstream cultural norms" (ibid. 1323). Latina women reported the highest and Black women the lowest levels of self-objectification in swimsuits. But also, Black women had the lowest loss of self-esteem and Latina the highest loss of selfesteem. Unlike Frederickson et al. (1998), Hebl et al. (2004) found that math performance on ten Graduate Record Examination questions was lowest in the sweater condition for women, but all the women students showed effects of wearing swimsuits. Black students had higher self-esteem, a more positive attitude, and more resilience to stigma toward their bodies than the other groups. Using different stimuli over the undergraduate student experience, Gillen and Lefkowitz 
(2012) found that for female compared to male students, taking courses raised awareness of body image and eating disorders, but that female students "appearance evaluation" remained less positive than the male students.

Haimovitz et al. (1993) and Tiggemann (2000) also hypothesized that body satisfaction was influenced by situational factors. Beach and dressing room situations made subjects more critical of their bodies. For Haimovitz et al. (1993), evaluation of individual body parts was more stable, and self-perceived weight and BMI were highly correlated (the lower the self-perceived weight rating, the lower the score for each situation). Tiggemann (2000) reported body satisfaction and esteem were lower in evaluations of legs, hips, and thighs. Esteem varied more for normal-weight women than for underand overweight ones. Normal-weight women were more responsive to situational context than thin or overweight counterparts. Small (2017) noted that the beach functioned as space "for sexualized bodies to be gazed upon and to gaze" but wearing swimsuits on the beach was stressful and "not a place for delicious abandonment" for women; many had to work hard to achieve "the required normative advantage" of looking good in swimsuits.

\section{Ethnicity and Body Image}

Ethnicity and culture have played large roles in defining body image and dissatisfaction. Ideal body image developed and became internalized through enculturation (Byrd-Bredbenner \& Murray, 2003; Paquette \& Raine, 2004). Anthropologists and others found that people in food-scarce societies valued larger-body size as signs of well-being (Lieberman \& Probart, 1992; Lieberman, 2017, 2018).
Racial and ethnic beauty preferences emphasized different body parts. White women were described as having "rigid" concepts of thinness, while Black women, and some Latina women preferred more curvaceous bodies (Schooler et al. 2012) and had less rigid ideals (Falconer \& Neville, 2000; Cox et al., 2010). Black women focused on body shape and dress instead of actual body-size and weight (Allan, et al., 1993; McClure, 2012; Anderson-Fye et al., 2012). Some low-income Black women in the Southeast U.S. (Alabama) accepted larger body-size in defiance of thinness ideals (Thomas \& De Cara, 2017). They were "fat-tolerant" with men and women selecting larger ideal female body-sizes (Rucker \& Cash, 1992; Bhuyian et al., 2003; McClure, 2012). Ethnicity made the acceptance of larger body size protective against body dissatisfaction of the thin-ideal (Lieberman, 2021). This correlated with lower incidence of eating disorders among Black women and reduced stigma associated with being overweight (Allan et al., 1993; Henriques et al., 1996; Molloy 1998).

Asian had more extreme notions of thinness than Whites. Studies attributed this to westernization and "cultural appreciation" (such as in Japan) of a thin-female figure (Matsuura et al. 1992 as cited in Barnett et al., 2001; Kawamura, 2012). Asian reported the lowest self-esteem when placed in objectification situations such as wearing "bathing suits." However, some Asian cultures traditionally valued full-figures as signs of prosperity. Women from Singapore, Hong Kong, and Japan were least satisfied with their physical appearance. Those from Japan and Taiwan were least satisfied with weight while those from the Philippines were satisfied with appearance and weight (Kawamura, 2012). 
Hebl et al. (2004) showed that Latina women had similar attitudes and beliefs to Whites in terms of self-esteem and body satisfaction, but the most shame in objectification situations compared to White, Black, and Asian participants. Schooler et al. (2012) found the opposite and suggested that some Latina women were buffered from body image concerns by a concept of the "thick body" or "buencuerpo". Warren et al. (2005) found that ethnicity had protective effects against body-dissatisfaction, with participants of Mexican origin being less susceptible to internalizing the thin-ideal and seeing curvaceous and larger bodies as attractive. That was not the finding from the South Beach women stratum in this study (many of whom had family origins in Brazil and other South American countries) who adopted the "chic look" and "thin-ideal".

\section{Hypotheses for the Study}

This research used anthropometric body measurements, standardized figure-rating scales, and swimwear rating scales (from conservative to revealing suits and places worn) to evaluate how women looked and felt in swimsuits. The following hypotheses were constructed based on the characteristics of the convenience samples (Table 1). To collect the data, subjects were asked first to measure their waist, hips, and bust ${ }^{7}$. The data were used to calculate WHR, WC, and BMI. The questionaries asked about types of suits worn (1-piece, 2-piece, bikini, and thong), in the presence of family, friends, beach/pool, and in private. All subjects voluntarily agreed to the study and were intrigued by the instruments

\footnotetext{
7 Self-measurement of waist, bust, chest, and hips were taken with project-supplied tape measures three times and averaged. Also used
}

used, physical measurements, questionnaires, and extensive narratives (to be analyzed subsequently). All signed the required consent form for the University of Florida Review Board.

General and specific hypotheses were developed that linked anthropometric measurements (WC, WHR, and BMI) with subjects' body image and self-esteem, and swimsuit choices (revealing or revealing the body), and places suits were worn.

\section{Self-Rating Scales}

The research incorporated and developed various rating scales to ascertain how participants felt about their bodies when wearing swimsuits. Subjects in the convenience samples evaluated their bodies in terms of: (1) a whole-body Figure Rating Scale (FRS) and the Chest/Breast Scale Figures, using the Waist Bust Ratio; (2) their self-esteem using the Body Cathexis Scale; and (3) how they felt about their bodies in "My Body Right Now".

Subjects also evaluated their swimwear usages and experiences. Two basic Swimwear Scales were devised. The first asked subjects to rate themselves in terms of types of swimsuits worn (scaled from 1-piece, 2-piece, bikini, to thong), and the second places they would wear the garments (in front of family, friends, strangers beachside, or in private situations ${ }^{8}$ )

\section{Figure Rating Scales}

In addition to the quantitative measurement data, women were asked to rate their own bodies in terms of specific figures to ascertain how they saw their

were self-reported height and three averaged weights (using the project's portable scales).

8 "In Private" encompassed locations other than beaches and pools, with others or alone.

Spring, A., and V. McClain (2021) That Swimsuit Reveals You: Body Image and Bathing Suits of Florida Women. New Florida Journal of Anthropology 2(1):37-68. DOI:10.32473/nfja.v2i1.124046 


\section{Hypotheses 1: Body Image and WC, BMI \& WHR}

Hypothesis 1a: Women with lower WC, BMI, and WHR have less body dissatisfaction than those who have higher measurements and ratios.

Hypothesis 1b: Women with normal and underweight BMIs have better body images.

Hypothesis 1c: Women closer to WHR “ 0.67 ” have better body image, self-esteem, and body satisfaction.

Hypothesis 1d: Fat-tolerant groups have preferences for higher BMIs and larger body shapes, supporting better body image, self-esteem, and body satisfaction.

\section{Hypotheses 2: Swimsuits and WC, BMI \& WHR}

Hypothesis 2a: Women with low BMI and WC prefer more-revealing suits, rate themselves higher, and have fewer fit problems.

Hypothesis 2b: Women with more symmetrical shapes wear more-revealing swimsuits, and rate themselves higher.

Hypothesis 2c: Fat-tolerant groups have preferences for higher BMIs and larger body shapes but prefer less-revealing suits. Swimwear for larger women in shapes and weights in past decade.

Hypothesis 2d: Fat-intolerant maintain body dissatisfaction throughout the lifespan; fattolerant increasingly have body acceptance throughout the lifespan.

bodies generally and in terms of their ideal types. Used widely in psychology, the original Figure Rating Scale/Silhouette Matching Test (SMT) measured perceptions of real and ideal body shape using nine full-body female figures from small to large (Stunkard et al., 1983). Discrepancy scores (ideal minus real or real minus ideal) provided estimates of body dissatisfaction (Fallon \& Rozin, 1985; Rozin, 2001; Bhuiyan et al., 2003; Silverstein et al., 1988; Gardner \& Brown, 2010). Doll et. al (2003) used the "the ordered array method" scale, for university students to choose their current, ideal, and socially acceptable figure. They found that an ordered method elicited a less favorable rating of larger body sizes. For the research reported here, the figures have been regrouped into the six BMI categories as determined by the National Institutes of Health (Figures $\mathbf{1}$ and $\mathbf{2}$ below).

Along with body measurements, the following instruments were used to ascertain women's perception of image and self-esteem. For the Figure Rating Scale (FRS), WHRs were aggregated by BMI categories and "real-minus-ideal-figures" and then correlated with physical measurements (BMI, WC, WHR and BWR), for the swimsuit variables. For Figure 1, this research used the original six figures (Stunkard et al. 1983) but then reduced to four figures, as two endpoint figures (smallest and largest) were not selected by any of the 372 participants. 
The Chest/Breast Scale (Waist Bust Ratio, WBR) measured perceptions of real and ideal body shape using nine female upper-torso drawings that reduced to five figures as the two end-figures on each side were not chosen. A discrepancy score (ideal minus real or real minus ideal) provided an estimate of body dissatisfaction (Figure 2).

\section{Verbal Rating Scales: Body Cathexis Scale (BCS4) and My Body Right Now (MBRN7)}

Body image and self-esteem have been related to behavior and attitudes, and many scales ranked "affect" related to body parts, word pairs, figure drawings, etc. (Tiggemann, 2001; Warren et al., 2005). The original Body Cathexis Scale, a measure of body self-esteem, had 46 items (Secord and Jourard, 1953). It was used by hundreds of researchers and was in the public domain. The present study initially used 31 items, finding only four (termed here "BCS4") were salient and predictive for describing women's attitudes towards their bodies. Similarly, "My Body Right Now" a widely used scale of 16-items (Leon, 1975; Diekmann, 1997) contained opposite pairs such as "fat-thin" and "flabby-firm" to measure participants' current feelings about their bodies. Seven of the 16 items were significant in this study and termed "MBRN7".

\section{Rate self in Swimwear (fit, lesser to more revealing, in front of which peo- ple and places worn)}

Several scales were constructed for this variable: (1) Rate-Self (3-point) and Fit (five-point) Likert Scales; (2) Most-Revealing Suit (MRS) (1-piece, 2piece, bikini, thong); and (3) swimsuits they would wear around family, friends, beachside, and in private.

\section{Results: Quantitative Data}

Table 1 earlier in the paper provided data on the numbers and ages of subjects for each sample. White, the largest category, included 185 participants (18-85 years). The samples included students (early 20s), North and South Florida women (40s-70s years), aqua-aerobic women (30s-70s years). Latina included students (early 20s), South Florida women and department-store shoppers (40s-50s years), and boutique shoppers (20s-40s years) who were surveyed at South Beach, in Miami. Competitors with the smallest age range (18-33 years), were mostly White, but also had Black, Latina, and Asian participants.

Statistical analyses were carried out on data from 372 participants. Consistent with the literature that body image dissatisfaction diminishes with age, participants were placed into three age-category groups (18-34, 35-54, 55 years and older). Additionally, the original sample was subsequently grouped into four racial/ethnic groups (White, Black, Latina, and Asian), plus the Competitors (Swimmers, Beauty Contestants, and Swimwear Models). Statistical analyses used these "standard" categories. Mean scores on self-ratings, correlations (Kendall's correlation coefficient), and regression analysis (ANOVA) were utilized as the data were skewed to younger participants.

The variables and tests that looked at age and body dissatisfaction were completed for the entire sample. The data showed that the relationship between age and the figures that respondents selected was weak, meaning that age alone did not have an impact on how women rated themselves or on how they felt in suits by situations. The expectations, based on the literature and on researchers' hypotheses, were that body 
dissatisfaction would diminish with age. But the findings showed that the older women in the sample continued to experience body dissatisfaction throughout their lifespan.

Anthropometric measurements: BMI, Weight, WC, WHR, and correlations with Body Image (FRS) and Body Satisfaction (MRS4 and BCS7)

Findings show that as BMI increased, participants perceived their body shape to be larger and no samples underestimated body shape (Table 2). Seventy percent of the total sample had normal BMI classifications; $21 \%$ were overweight or obese, and $9 \%$ were underweight (Table 2). Twenty-two percent of Whites, $44 \%$ of Latina, and $39 \%$ of Blacks had weights above normal, while $28 \%$ of Asian and $15 \%$ of Competitors were underweight. Competitors were the most homogeneous group ( $S D=2.1$ ), whereas Blacks had the highest standard deviation $(S D=6.8)$ meaning that they were most likely to include both fat-intolerant and fat-tolerant women in the category.
Simple frequencies on weight satisfaction (Table 3 ) showed that $36 \%$ were satisfied with their weight; $27 \%$ felt a strong desire to change, $18 \%$ did not like their weight but "put up with it", and $10 \%$ were in the middle. Competitors $($ Mean $=3.2)$ and Asians $($ Mean $=2.9)$ were the most satisfied with their weight and had the highest mean scores. Only half of the White, Latina, Black, and Asian groups were satisfied with their weight, compared to most of the Competitors who were satisfied.

"Weight" as a variable had the strongest relationship with BMI. The Body Cathexis Scale 7 variables were rated on a five-point Likert scale (table not shown). Except for the variable "Bust" (Chest size) all variables had a moderate to low correlation with BMI. The values were: Weight $\left(\mathrm{T}=0-.512^{* *}\right)$, Waist $(\mathrm{T}=$ $\left.0.403^{* *}\right)$, Hips $\left(\mathrm{T}=-0.362^{* *}\right)$, Body build $(\mathrm{T}$ $\left.=-0.423^{* *}\right)$, Energy $\left(\tau=-0.232^{\star *}\right)$, and Appetite $\left(\mathrm{T}=-0.323^{\star *}\right)$.

Table 4 shows a strong correlation between BMI and waist circumference (WC) for all samples $\left(\tau=-0.830^{\star *}\right)$, but a weak correlation with WHR ( $\mathrm{r}=$

Table 2. Percent of respondents by BMI classification with mean BMI.

BMI CATEGORIES

\begin{tabular}{|c|c|c|c|c|c|c|c|c|}
\hline Sample & $\begin{array}{c}\text { Under- } \\
\text { Weight } \\
\%\end{array}$ & $\begin{array}{c}\text { Normal } \\
\% \\
\end{array}$ & $\begin{array}{c}\text { Over- } \\
\text { Weight } \\
\%\end{array}$ & $\begin{array}{c}\text { Obese } \\
\text { I } \\
\% \\
\end{array}$ & $\begin{array}{c}\text { Obese } \\
\text { II } \\
\% \\
\end{array}$ & $\begin{array}{c}\text { Morbid } \\
\text { Obesity } \\
\%\end{array}$ & $\begin{array}{c}\text { Mean } \\
\text { BMI }\end{array}$ & $\begin{array}{l}\text { BMI Stand- } \\
\text { ard Devia- } \\
\text { tion }\end{array}$ \\
\hline White & 3.6 & 74.5 & 12.7 & 7.3 & 1.8 & & 23.2 & 4.07 \\
\hline Latina & 6.3 & 50.0 & 31.3 & 12.5 & & & 23.9 & 4.34 \\
\hline Asian & 27.6 & 65.5 & 3.4 & & 3.4 & & 21.0 & 3.83 \\
\hline Black & 8.9 & 51.1 & 20.0 & 8.9 & 6.7 & 4.4 & 25.2 & 6.79 \\
\hline Competitors* & 14.9 & 83.6 & 1.5 & & & & 20.7 & 2.10 \\
\hline Total & 8.9 & 70.1 & 12.4 & 5.9 & 2.1 & 0.6 & 22.9 & 4.48 \\
\hline
\end{tabular}

*Swim Team may be placed in the overweight category due to increased height and larger body size.

Spring, A., and V. McClain (2021) That Swimsuit Reveals You: Body Image and Bathing Suits of Florida Women. New Florida Journal of Anthropology 2(1):37-68. DOI:10.32473/nfja.v2i1.124046 
$0.345^{* *}$. Participants' BMls had a high association for all samples with the Real Body Figure Rating Scale (FRS). For the Ideal FRS, BMI was only significant for White, Latina, and Black samples. Asian and Competitor samples were closer to or at their ideal body shape and had no significant associations.

BMI also correlated with most revealing suit worn (Table 5) in terms of Family $\left(\mathrm{T}=0.440^{* *}\right)$, Friends $\left(\mathrm{T}=0.520^{* *}\right)$, at the Beach $\left(\mathrm{T}=0.540^{* *}\right)$, and in Private $\left(\mathrm{T}=0.549^{* *}\right)$. The correlations are highly significant for Whites, Latina, and Blacks, but less so for Asians and Competitors. BMI also showed a moderate relationship for all samples except for Competitors when correlated with Rate Self in Swimsuit $\left(\mathrm{T}=-0.452^{* \star}\right)$.

There were no correlations with Real Chest FRS and Difficulty of Fit, most likely because the industry had created numerous tops and brassiere-type sizing to reduce the problems. The correlation of BMI with Real and Ideal Chest/Breast FRS was weak and only had a moderate correlation for the White $\left(\tau=0.477^{* *}\right)$ and Black $\left(\mathrm{T}=0.430^{* *}\right.$ and $\left.0.401^{* *}\right)$ samples.

\section{Swimsuit Usage Variables: Most Re- vealing Suit, Rate Self, and Suit Fit}

\section{as Correlated with BMI and Body Im- age Variables (MBRN and BCS7)}

In considering how these variables impinge on revealing the body, most subjects rated their appearance in a swimsuit as average (68\%), $15 \%$ rated below average, and $17 \%$ above average. Surprisingly, only $34 \%$ of competitors rated themselves highly.

Participants also selected the most revealing suit (1-piece, 2-piece, bikini, and thong) they would feel comfortable wearing in each of four situations (family, friends, beachside, and privately). Data from tables (not shown here) list $44 \%$ of the total feeling comfortable wearing a bikini with their family, compared to $33 \%$ who preferred a 2-piece, $22 \%$ who preferred a 1 -piece, and $1 \%$ who would wear a thong. Considering friends, $49 \%$ of the total were comfortable wearing a bikini, $28 \%$ a 2 -piece, $20 \%$ a 1 -piece, and $3 \%$ a thong. What to wear at the beach? Of the total, $52 \%$ chose a bikini; $20 \%$ a 2 -piece, $21 \%$ a 1 -piece, and $2 \%$ a thong. In private, more women revealed their bodies: most chose a bikini (43\%), then a 2-piece $(23 \%)$, a thong $(22 \%)$, and a 1 -piece $(13 \%)$.

Table 5 also shows that BMI correlated with "Most Revealing Suit" and "Rate Self in Swimsuit" for all

Table 3. Feelings about weight by sample and mean total score (in percent) (1=Strong Desire to Change, 2=Don't like but "Put Up With, 3=No Feelings/Don't Care, 4=Am Satisfied, 5-Consider Myself Fortunate).

\begin{tabular}{cccccc|c} 
Sample & $\mathbf{1}$ & $\mathbf{2}$ & $\mathbf{3}$ & $\mathbf{4}$ & $\mathbf{5}$ & $\begin{array}{c}\text { Mean Total } \\
\text { Score }\end{array}$ \\
\hline White & 32.1 & 16.3 & 7.1 & 37.0 & 7.6 & 2.7 \\
Latina & 35.3 & 14.7 & & 38.2 & 11.8 & 2.8 \\
Asian & 20.7 & 20.7 & 13.8 & 34.5 & 10.3 & 2.9 \\
Black & 31.4 & 21.6 & 7.8 & 29.4 & 9.8 & 2.6 \\
Competitors & 10.0 & 18.6 & 20.0 & 38.6 & 12.9 & 3.2 \\
Total & $\mathbf{2 7 . 2}$ & $\mathbf{1 7 . 7}$ & $\mathbf{9 . 5}$ & $\mathbf{3 6 . 1}$ & $\mathbf{9 . 5}$ & $\mathbf{2 . 8}$
\end{tabular}

Spring, A., and V. McClain (2021) That Swimsuit Reveals You: Body Image and Bathing Suits of Florida Women. New Florida Journal of Anthropology 2(1):37-68. DOI:10.32473/nfja.v2i1.124046 
participants, except Asian and Competitors. Asians usually would not reveal their bodies in front of family, friends, or beachside (as described in the swimsuit narratives not analyzed here), whereas Competitors with near "perfect" bodies felt comfortable in wearing the same more revealing suits in all situations. These two samples had low BMls. For all other samples, as BMI increased, less-revealing suits were worn in front of family and friends, at the beach, and in private. Age was less strong a factor. The moderate associations appear for Friends $\left(\tau=0.520^{* *}\right)$ and Beach $(\tau=$ $0.540^{* *}$, marking those as situations when participants were critical of their appearance and size.

The Body Cathexis Scale asked about waist satisfaction (table not shown) shown); and results showed that groups less satisfied with their waist size $(\mathrm{T}=$ $0.445^{\star *}$ ) and had a higher WHR compared to others. BMI had a weaker negative relationship with BWR.

The My Body Right Now (MBRN4) items (fat/thin, heavy/light, large/small and flabby/firm) were correlated with the most revealing suit in Table 6 . Results showed that the White and Latina samples related their feelings about the "fatness" of their bodies with the type of suits they wore in all situations, with Latinas wearing more revealing suits in front of family $\left(\tau=-0.634^{\star *}\right)$. For the Black sample, this was true only for the beach $(\tau=$ $\left.0-597^{\star *}\right)$ and in private $\left(\mathrm{T}=0-.527^{* *}\right)$. All groups, including Competitors and Asians, had moderate correlations between how they rated themselves and

\footnotetext{
${ }^{9}$ In the Body FRS, each of the nine figures represented a predetermined BMI. Participants chose the figure they perceived themselves to be (Real) and their desired figure (Ideal). During data collection, some participants commented on being dissatisfied with how the figures were drawn.
}

how they felt about their body density and firmness.

\section{Body Image (Body and Chest Figure Rating Scales: Real versus Ideal) and Self Esteem (BCS7 and MBRN4)}

In the Body Figure Rating Scale, each of the nine figures represents a predetermined BMI. Participants chose the body figure that they perceived as their own (Real), as well as their desired body shape (Ideal).

Figure 1 plots mean BMl and figures by stratum. Only four of the original nine figure shapes (numbers 2, 3, 4, and 5 ) that correlated with the BMI scores 20 28 are shown here because the others were not selected. BMI contrasted with real body shape plotted as a graphic for all samples. This meant that for real and ideal figures (plotted below the figures) Latina (Mean $=4.9$ and 3.3) and Blacks had the highest (Mean $=4.4$ and 3.5), while Competitors (Mean $=3.1$ and 2.4) and Asians (Mean = 3.7 and 2.9) had the lowest scores. ${ }^{9}$

Table 7 shows differences between real and ideal body shapes calculated to ascertain body satisfaction (FalIon and Rosen 1985; Silverstein 1988). The calculated differences between Real and Ideal Body FRS were significant for all samples. Table 8 shows only $22 \%$ of all participants were satisfied with their size; $70 \%$ wanted to be $1-5$ sizes smaller, while $9 \%$ wanted to be 1 5 sizes larger. Most satisfied and only wanting to be one size smaller, were the Competitors $(35 \%)$, and least satisfied were Whites (16\%) and Latina (20\%).

They felt that the images did not capture true changes in body shape, but only changes in weight. Participants also commented that the figures were selective and may have skipped an "in between" shape. 
Table 4. BMI correlated with real and ideal body FRS, real and ideal chest FRS, waist circumference, and WHR

\begin{tabular}{|c|c|c|c|c|c|c|c|}
\hline BMI & $\begin{array}{c}\text { Real } \\
\text { Body } \\
\text { FRS }\end{array}$ & $\begin{array}{c}\text { Ideal } \\
\text { Body } \\
\text { FRS }\end{array}$ & $\begin{array}{c}\text { Diff of } \\
\text { Real/ldeal } \\
\text { body } \\
\text { FRS }\end{array}$ & $\begin{array}{c}\text { Real } \\
\text { Chest } \\
\text { FRS }\end{array}$ & $\begin{array}{l}\text { Ideal } \\
\text { Chest } \\
\text { FRS }\end{array}$ & $\begin{array}{l}\text { Waist } \\
\text { Cir. } \\
\text { (WC) }\end{array}$ & Wh \\
\hline & & & $-0.523\left(^{\star \star}\right)$ & & & & 0.3 \\
\hline Lati & & & & & & $0.829\left(^{(* *}\right)$ & 0.4 \\
\hline Asian & $\left({ }^{* *}\right)$ & 0.2 & -0.6 & 0.4 & 0 & $0.843\left(^{* *}\right)$ & $0.386\left(^{*}\right)$ \\
\hline Black & $\left({ }^{* *}\right)$ & $0.589\left(^{* \star}\right)$ & $-0.776\left(^{* *}\right)$ & $0.430\left(^{* *}\right)$ & $0.401\left(^{* *}\right)$ & $0.832\left(^{* *}\right)$ & 0.261 \\
\hline Competitors & $\left.0.6611^{* *}\right)$ & 0.177 & $-0.628\left(^{* *}\right)$ & -0.178 & -0.116 & $0.725\left(^{\star *}\right)$ & $0.455\left(^{* *}\right)$ \\
\hline Total & $\left({ }^{* *}\right)$ & $0.524\left({ }^{\star *}\right)$ & & $0.365\left(^{\star *}\right)$ & $0.227\left(^{\star \star}\right)$ & $0.83^{\circ} 0\left(^{* *}\right)$ & $0.345\left({ }^{* *}\right)$ \\
\hline
\end{tabular}

$\left({ }^{* *}\right.$ indicates $p$-value sig. at .01; * sig. at .05)

Table 5. BMI correlated with most revealing suit, rate self in swimsuit, and mean BMI.

\begin{tabular}{|c|c|c|c|c|c|c|c|}
\hline \multirow{2}{*}{ BMI } & \multicolumn{4}{|c|}{ Most Revealing Suit } & \multirow[b]{2}{*}{ Rate Self } & \multirow[b]{2}{*}{ Fit } & \multirow[b]{2}{*}{$\begin{array}{c}\text { Mean } \\
\text { BMI }\end{array}$} \\
\hline & Family & Friends & Beach & Private & & & \\
\hline White & $\overline{0.418(* \star)}$ & $\left.0.455^{(* *}\right)$ & $\left.0.480{ }^{(* *}\right)$ & $0.412\left(^{* *}\right)$ & $-0.472\left(^{\star *}\right)$ & $\left.-0.3199^{* \star}\right)$ & 23.3 \\
\hline Latina & $\left.0.5211^{* *}\right)$ & $0.515\left(^{* *}\right)$ & $0.624\left(^{* *}\right)$ & $\left.0.5211^{* *}\right)$ & $-0.413\left(^{*}\right)$ & -0.278 & 23.9 \\
\hline Asian & 0.319 & $0.317\left(^{*}\right)$ & $0.465\left(^{*}\right)$ & $\left.0.370{ }^{*}{ }^{*}\right)^{\prime}$ & $-0.455\left(^{*}\right)$ & $-0.528\left({ }^{* *}\right)$ & 21.0 \\
\hline Black & $0.490\left(^{* *}\right)$ & $0.680\left({ }^{\star \star}\right)$ & $0.616\left(^{* *}\right)$ & $\left.0.6288^{(* \star}\right)$ & $-0.535\left(^{* \star}\right)$ & $\left.-0.4111^{* *}\right)$ & 25.2 \\
\hline Competitors & -0.152 & 0.129 & $0.309\left(^{*}\right)$ & $0.280\left(^{*}\right)$ & -0.165 & -0.226 & 20.7 \\
\hline Total & $0.440\left(^{* *}\right)$ & $0.520\left(^{* \star}\right)$ & $0.540\left(^{* \star}\right)$ & $\left.0.4899^{* \star}\right)$ & $-0.452\left(^{\star \star}\right)$ & $\left.-0.3699^{* \star}\right)$ & 22.9 \\
\hline
\end{tabular}

Table 6. MBRN4 correlated with most revealing suit (family, friends, beach, and private), difficulty of fit, and rate self.

\begin{tabular}{|c|c|c|c|c|c|c|}
\hline MBRN4 & Family & Friends & Beach & Private & Fit & Rateself \\
\hline White & $\left.-0.241{ }^{* *}\right)$ & $-0.240\left(^{* *}\right)$ & $-0.277\left(^{\star \star}\right)$ & $-0.226\left(^{* *}\right)$ & $-0.328\left(^{* *}\right)$ & $0.522\left({ }^{* *}\right)$ \\
\hline Latina & $-0.634\left(^{* \star}\right)$ & $-0.438\left(^{*}\right)$ & $-0.573\left(^{* \star}\right)$ & $-0.524\left(^{\star \star}\right)$ & $-0.547\left(^{* *}\right)$ & $0.492\left(^{* *}\right)$ \\
\hline Asian & -0.229 & -0.354 & -0.328 & -0.181 & -0.194 & $0.580\left(^{* *}\right)$ \\
\hline Black & $-0.321\left(^{*}\right)$ & $-0.514\left({ }^{* *}\right)$ & $-0.597\left(^{* *}\right)$ & $-0.527\left(^{* *}\right)$ & $-0.473\left(^{* *}\right)$ & $0.568\left(^{* *}\right)$ \\
\hline Competitors & $0.242\left(^{*}\right)$ & 0.033 & -0.120 & -0.071 & -0.123 & $0.438\left(^{* *}\right)$ \\
\hline Total & $-0.291\left(^{(* \star}\right)$ & $-0.334\left(^{* \star}\right)$ & $-0.386\left(^{\star \star}\right)$ & $\left.-0.321{ }^{(\star *}\right)$ & $-0.366\left(^{* \star}\right)$ & $0.539\left(^{* *}\right)$ \\
\hline
\end{tabular}

MBRN4 items: Fat/Thin, Heavy/Light, Large/Small, Flabby/Firm.

$\left(^{* *}\right.$ indicates $p$-value sig. at .01; * sig. at .05) 
Twenty-four percent of Asians wanted to be 1-2 sizes larger. Competitors, the most likely to have "ideal" bodies, reported being under more scrutiny in their lives than other samples concerning weight and body proportions. For the Black sample $27 \%$ were satisfied, $43 \%$ wanted to be $1-2$ sizes smaller, while $14 \%$ wanted to be larger.

Figure 2 plots mean Real and Ideal Chest/Bust FRS based on five graphic figures ${ }^{10}$. Participants choose their real and ideal bust/chest sizes. It was obvious that the means were closer together than for the body Figure Rating Scale. Although chest/bust/breast size is a highly discussed and criticized area of the female body, participants expressed less concern about bust size than about body shape. Ideal figures chosen were larger for all samples, with Asians (Mean $=2.0$ and 3.1) and Competitors (Mean = 2.5 and 3.2 ) being the largest.

Table 8 shows that a third of the total sample were satisfied with their chest/breast (compared to only $22 \%$ of their body shape (Table 7) with Asians (17\%) being the least satisfied and Latinas being the most (40\%). Of the Competitors, $22 \%$ were satisfied, while surprisingly, $66 \%$ wanted to be $1-5$ sizes larger. The more detailed sample analysis showed that swimwear models, many of whom have had breast augmentation were content, while the swim-team members desired larger busts, but not chest size. ${ }^{11}$ In all, it was conjectured that there was greater satisfaction with the bust in general, and because breast augmentation was available for many women.

However, it should be noted that women swim team competitors had larger chest capacities needed for optimal air intake and breathing for their sport. They noted in their narratives that their upper-body chest areas were larger than non-competitor women, and that chest size differed from breast size. Most of the swimmers thought their breasts were too small. They had not had breast augmentation, since larger breasts could affect performance speeds.

Table 7. Percent of difference in real and ideal body FRS by sample.

\begin{tabular}{cccc|c|ccc} 
Stratum & $\begin{array}{c}\mathbf{3 - 5} \\
\text { sizes } \\
\text { smaller }\end{array}$ & $\begin{array}{c}\mathbf{2} \\
\text { sizes } \\
\text { smaller }\end{array}$ & $\begin{array}{c}\mathbf{1} \\
\text { size } \\
\text { smaller }\end{array}$ & Satisfied & $\begin{array}{c}\mathbf{1} \\
\text { size } \\
\text { larger }\end{array}$ & $\begin{array}{c}\mathbf{2} \\
\text { sizes } \\
\text { larger }\end{array}$ & $\begin{array}{c}\mathbf{3 - 5} \\
\text { sizes } \\
\text { larger }\end{array}$ \\
\hline White & 20.4 & 24.9 & 32.6 & 16.0 & 4.4 & 1.1 & 0.6 \\
Latina & 34.3 & 11.4 & 28.6 & 20.0 & 2.9 & 0.0 & 2.9 \\
Asian & 13.8 & 20.7 & 17.2 & 24.1 & 13.8 & 10.3 & 0.0 \\
Black & 14.3 & 20.4 & 22.4 & 26.5 & 12.2 & 2.0 & 2.0 \\
Competitors & 3.5 & 21.1 & 35.1 & 35.1 & 1.8 & 3.5 & 0.0 \\
Total & $\mathbf{1 7 . 7}$ & $\mathbf{2 1 . 9}$ & $\mathbf{2 9 . 9}$ & $\mathbf{2 1 . 7}$ & $\mathbf{5 . 7}$ & $\mathbf{2 . 3}$ & $\mathbf{0 . 9}$
\end{tabular}

\footnotetext{
10 The original protocol had 9 figures, but the two smallest and two largest were not chosen by subjects here.
}

\footnotetext{
${ }^{11}$ This was not asked in the instruments used here, but some subjects remarked on it in the narratives.

There were comments about the figures not showing true chest size, but rather weight changes.
}

Spring, A., and V. McClain (2021) That Swimsuit Reveals You: Body Image and Bathing Suits of Florida Women. New Florida Journal of Anthropology 2(1):37-68. DOI:10.32473/nfja.v2i1.124046 
Figure 1. Mean actual, real, and ideal body FRS by sample.

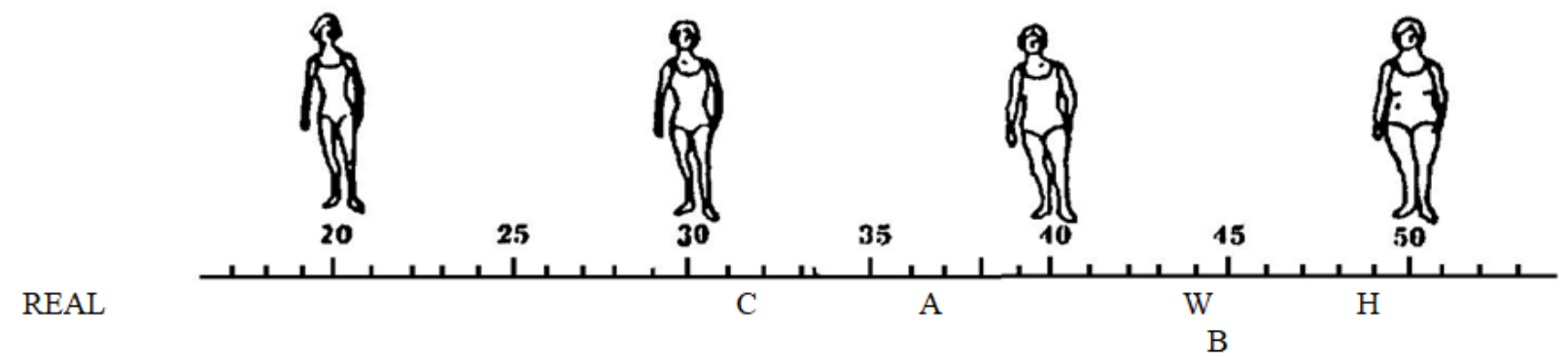

IDEAL $\quad$ C $\quad$ A $^{\text {W }}{ }_{\text {B }}^{\text {H }}$

\begin{tabular}{cc|c|c|c}
\multicolumn{2}{c|}{ Sample } & $\begin{array}{c}\text { MEAN REAL } \\
\text { FRS }\end{array}$ & $\begin{array}{c}\text { MEAN IDEAL } \\
\text { FRS }\end{array}$ & MEAN BMI \\
\hline W & White & 4.4 & 2.9 & 23.2 \\
L & Latina & 4.9 & 3.3 & 23.9 \\
A & Asian & 3.7 & 2.9 & 21.0 \\
B & Black & 4.4 & 3.5 & 25.2 \\
C & Competitors & 3.1 & 2.4 & 20.7
\end{tabular}

Only three of the seven Body Cathexis Scale characteristics correlated with the Real FRS. Table 9 shows that these were Weight $\left(\mathrm{T}=-0.593^{\star *}\right)$, Waist $\left(\mathrm{T}=-0.445^{\star *}\right)$, and Body Build $\left(T=-0.498^{\star \star}\right)$, and they obtained for all samples. Energy and Appetite were significant only for Whites ( $\mathrm{T}$
$=-0.402^{* *}$ and $\left.-0.369^{* *}\right)$ and Latina $(\mathrm{T}=-$ $0.436^{\star *}$ and $\left.-0.329^{\star *}\right)$. Appetite was significant for the Competitors $\left(\mathrm{T}=-0.351^{\star *}\right)$. Body build was a significant attribute for all samples $\left(\mathrm{T}=-0.498^{* *}\right)$, as were Hips for Blacks $(\mathrm{T}=-0.419)$ and Competitors $(\mathrm{T}$ $\left.=-0.343^{* *}\right)$. Again, there are no

Table 8: Percent of Difference in Real and ldeal Chest FRS by sample.

\begin{tabular}{c|ccc|ccc|ccc} 
Sample & $\begin{array}{c}\mathbf{3 - 5} \\
\text { sizes } \\
\text { smaller }\end{array}$ & $\begin{array}{c}\mathbf{2} \text { sizes } \\
\text { smaller }\end{array}$ & $\begin{array}{c}\mathbf{1} \text { size } \\
\text { smaller }\end{array}$ & $\begin{array}{c}\mathbf{1} \text { size } \\
\text { larger }\end{array}$ & $\begin{array}{c}\mathbf{2} \text { sizes } \\
\text { larger }\end{array}$ & $\begin{array}{c}\mathbf{3} \mathbf{- 5} \\
\text { sizes } \\
\text { larger }\end{array}$ & Smaller & Larger & Satisfied \\
\hline White & $1.7 \%$ & $5.0 \%$ & $17.8 \%$ & $25.0 \%$ & $13.9 \%$ & $1.7 \%$ & $24.5 \%$ & $40.6 \%$ & $35.0 \%$ \\
Latina & - & $5.7 \%$ & $11.4 \%$ & $25.7 \%$ & $11.4 \%$ & $4.0 \%$ & $11.4 \%$ & $41.1 \%$ & $40.0 \%$ \\
Asian & $3.4 \%$ & - & $6.7 \%$ & $27.6 \%$ & $37.9 \%$ & $6.9 \%$ & $10.1 \%$ & $72.4 \%$ & $17.2 \%$ \\
Black & $2.0 \%$ & $6.1 \%$ & $14.3 \%$ & $24.5 \%$ & $12.2 \%$ & $4.1 \%$ & $22.4 \%$ & $40.8 \%$ & $36.7 \%$ \\
Competitors & - & $3.4 \%$ & $8.6 \%$ & $34.5 \%$ & $29.3 \%$ & $1.7 \%$ & $12.0 \%$ & $65.5 \%$ & $22.4 \%$ \\
Total & $\mathbf{1 . 4} \%$ & $\mathbf{4 . 6 \%}$ & $\mathbf{1 4 . 2} \%$ & $\mathbf{2 6 . 8} \%$ & $\mathbf{1 7 . 9} \%$ & $\mathbf{2 . 9} \%$ & $\mathbf{2 0 . 2} \%$ & $\mathbf{4 7 . 6 \%}$ & $\mathbf{3 2 . 2} \%$
\end{tabular}


associations for bust. Groups who felt dissatisfied with their body shape expressed this when there were increases in BMI or increases in their waist circumference.

\section{Analysis of Variance for all Variables}

One-way ANOVA tests were used to examine the association of samples with all measures used in the study (Table 10). Results for all categories show that there were significant values in all measures used except waist-hip-ratio (WHR) and Ideal Chest FRS ( $F=.510$ and 1.285). "Bonferroni Comparisons" (a significance test that uses differences in means) showed several significant differences between samples. For physical measures (BMI, WC, WHR), Competitors and Asians had lower mean BMls when compared to White, Latina, and Black women. There were significant differences for WC, with Competitors and Asians being similar, as were Latinas and Whites; the greatest difference for this variable was in the Black sample. For the Real Body FRS, Competitors and Asians were similar as were Whites, Blacks, and Latinas. For Ideal FRS, Competitors and Asians again were similar, as were Whites and Latinas, but the Black sample showed a higher mean, reflecting greater appreciation of a larger body size, and less influence of the thin-ideal. The calculated discrepancy scores for Body FRS showed the most significant difference between Asian and Latina samples because the

Figure 2. Mean real and ideal chest FRS by sample.
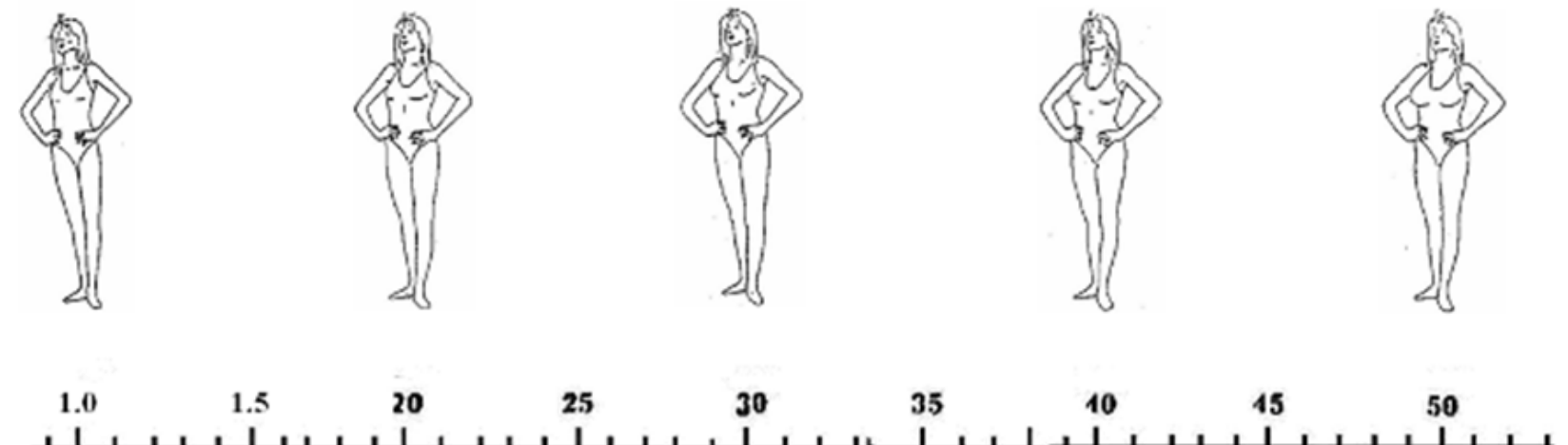

REAL $\quad$ A $\quad$ C $\quad H \quad$ W B

IDEAL

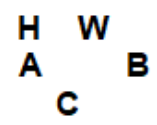

\begin{tabular}{ll|c|c|c}
\multicolumn{2}{c|}{ Sample } & MEAN REAL FRS & MEAN IDEAL FRS & MEAN BMI \\
\hline W & White & 3.0 & 3.3 & 23.2 \\
L & Latina & 2.7 & 3.1 & 23.9 \\
A & Asian & 2.0 & 3.1 & 21.0 \\
B & Black & 3.1 & 3.4 & 25.2 \\
C & Competitors & 2.5 & 3.2 & 20.7
\end{tabular}

Spring, A., and V. McClain (2021) That Swimsuit Reveals You: Body Image and Bathing Suits of Florida Women. New Florida Journal of Anthropology 2(1):37-68. DOI:10.32473/nfja.v2i1.124046 
latter wanted to be $2-5$ sizes smaller. The Real Chest FRS showed significant differences for Competitors and Asians compared to other groups. The greatest difference in the calculated discrepancy scores for Chest FRS was between Whites and Competitors reflecting that Whites in both categories were influenced by the thin-ideal.

For Most Revealing Suit, sample differences accounted for the variance in all four situations (family, friends, beachside, and in private). For these four situations, Bonferroni comparisons showed the Competitors on average, selected more-revealing suits when compared to Whites, Latinas, Blacks, and Asians. In Private, Competitors had a significant difference in wearing revealing suits in all situations, while Blacks and Asians tended to wear more conservative suits around their families.

Rateself in a swimsuit and Difficulty of Fit scales again showed that Competitors had significant differences in means when compared to the other categories. They rated their appearance higher than other groups and had little difficulty with fit, meaning that both normal and obese women saw themselves as having difficulties with swimsuits.

In terms of the measures of selfesteem, individual items from the BCS7 scale showed sample differences were small. When the seven items were scored separately, Competitors scored an average of 3.4 points higher on those items than Whites. For the two most salient variables (Feelings about Weight and Waist) some differences were noticed. For Feelings about Weight, Blacks and Asians had slightly higher means for opposite reasons. For Feelings about Waist, Competitors were different from all other samples. The second measure of self-esteem from the "MBRN4", only showed significant differences between Competitors, Whites, and Latinas, with Competitors scoring an average of 1.7 and 2.7 higher for those items.

\section{Discussion of Samples}

In terms of the specific 16 cultural/ethnic groups that make up the five grouped samples, some specific characteristics should be noted. For the Competitor sample, the Swim Team was more conservative compared to Swimsuit Models and Pageant Contestants in terms of revealing suits (e.g., thongs). As noted above, Swim Team members had larger chests and smaller bust sizes. They said that they would have preferred chest sizes one size smaller and bust sizes 2 sizes larger (following standard preferences for women), but they could not have these preferences as competitive swimmers as breast augmentation might have lowered their speeds and diving performances.

Pageant Contestants rated themselves poorly as their BMI increased; they were satisfied with weight but not with their waists. Swimwear Models, the sample with the lowest BMI, were most satisfied with their weight and waists, but some who did not have breast augmentation wanted their busts to be 1 to 2 sizes larger and their bodies to be one size smaller. The research showed that the "thin-ideal" affects women even with the most ideal bodies.

Asians in the sample had low BMls but still wanted to be 1-2 sizes smaller in body size; they wanted to be 1 2 sizes larger in the bust, but breast augmentation was not prevalent in this sample. They were satisfied with their weight and waist, but none of these factors affected the swimsuits they wore, as cultural norms seemed to mandate a con- 
Table 9. Real body figure rating scale correlated by BCS7 by sample. (Note: "Bust" omitted--was not significant).

\begin{tabular}{|c|c|c|c|c|c|c|}
\hline \multicolumn{7}{|c|}{ Body Cathexis Scale Items (BCS7) } \\
\hline $\begin{array}{l}\text { Real Body } \\
\text { FRS }\end{array}$ & Weight & Waist & Hips & $\begin{array}{l}\text { Body } \\
\text { build }\end{array}$ & Energy & Appetite \\
\hline White & $-0.622\left(^{* *}\right)$ & $-0.447\left(^{* *}\right)$ & -0.448 & $0.496\left({ }^{* *}\right)$ & $-0.402\left({ }^{* *}\right)$ & $-0.369\left(^{* *}\right)$ \\
\hline Latina & $\left.-0.630{ }^{* *}\right)$ & $-0.372\left(^{\star}\right)$ & $-0.429\left(^{\star}\right)$ & $-0.647\left({ }^{* \star}\right)$ & $-0.436\left(^{* \star}\right)$ & $-0.329\left(^{* *}\right)$ \\
\hline Asian & $-0.607\left(^{* \star}\right)$ & $-0.611\left(^{* *}\right)$ & -0.276 & $-0.561\left({ }^{* *}\right)$ & -0.347 & -0.277 \\
\hline Black & $-0.525\left(^{* *}\right)$ & $\left.-0.423^{(* *}\right)$ & $-0.419\left(^{\star \star}\right)$ & $\left.-0.4099^{* \star}\right)$ & -0.063 & $-0.306\left(^{*}\right)$ \\
\hline Competitors & $-0.578\left(^{* \star}\right)$ & $-0.368\left(^{* \star}\right)$ & $-0.343\left({ }^{* *}\right)$ & $\left.-0.3599^{* *}\right)$ & -0.070 & $\left.-0.3511^{* *}\right)$ \\
\hline Total & $-0.593\left({ }^{\star \star}\right)$ & $-0.445\left({ }^{* \star}\right)$ & -0.387 & $-0.498(* *)$ & $-0.294(* *)$ & $-0.316(* *)$ \\
\hline
\end{tabular}

Table 10. ANOVA with strata means for all instruments and scales.

\begin{tabular}{l|c|ccccc}
\multicolumn{1}{c}{ Variables } & F score & White & Latina & Asian & Black & Competitors \\
\hline BMI & $9.605^{* *}$ & 23.3 & 23.7 & 21.0 & 25.2 & 20.7 \\
Waist Circumference & $6.500^{* *}$ & 30.9 & 31.1 & 28.4 & 32.2 & 28.3 \\
WHR & .510 & .789 & .774 & .784 & .795 & .780 \\
Real Body FRS & $8.927^{* *}$ & 4.4 & 4.9 & 3.7 & 4.4 & 3.1 \\
Ideal Body FRS & $9.078^{* *}$ & 3.0 & 3.3 & 3.0 & 3.5 & 2.4 \\
Discrepancy Score & $4.227^{* *}$ & -1.46 & -1.56 & -.759 & -.939 & -.793 \\
(Body) & & & & & & \\
Real Chest FRS & $6.309^{* *}$ & 3.1 & 2.6 & 2.0 & 3.1 & 2.5 \\
Ideal Chest FRS & 1.285 & 3.3 & 3.1 & 3.1 & 3.4 & 3.2 \\
Discrepancy Score & $4.870^{* *}$ & .233 & .444 & 1.07 & .286 & .814 \\
(Chest) & & & & & \\
M. Revealing Suit & $13.610^{* *}$ & 3.5 & 3.2 & 3.6 & 3.7 & 2.2 \\
Family & $16.918^{* *}$ & 3.5 & 2.9 & 2.9 & 3.4 & 2.0 \\
M. Revealing Suit & $15.338^{* *}$ & 3.5 & 3.0 & 3.0 & 3.4 & 2.0 \\
Friends & $10.095^{* *}$ & 2.9 & 2.4 & 2.6 & 2.8 & 1.6 \\
M. Revealing Suit & & & & & & \\
Beach & & & & & & \\
M. Revealing Suit Pri- & & & & & & \\
vate & & & & & \\
Rate Self in a Swimsuit & $9.579^{* *}$ & 1.9 & 1.9 & 1.8 & 2.0 & 2.4 \\
Fit & $12.098^{* *}$ & 3.4 & 3.6 & 3.6 & 3.0 & 2.4 \\
Feelings about Weight & $2.900^{* *}$ & 2.76 & 2.83 & 3.03 & 3.06 & 2.76 \\
Feelings about Waist & $2.505^{* *}$ & 2.68 & 2.80 & 2.93 & 2.65 & 3.27 \\
Body Cathexis Scale & $3.879^{* *}$ & 20.7 & 21.1 & 21.0 & 22.7 & 24.1 \\
(7) & & & & & \\
My Body Right Now (4) & $4.085^{* *}$ & 12.9 & 11.9 & 13.4 & 13.1 & 14.6 \\
\hline ( & & & & &
\end{tabular}

${ }^{* *}$ indicates $p$-value sig. at .01; * sig. at .05)

Spring, A., and V. McClain (2021) That Swimsuit Reveals You: Body Image and Bathing Suits of Florida Women. New Florida Journal of Anthropology 2(1):37-68. DOI:10.32473/nfja.v2i1.124046 
servative 1-piece suit (especially in front of family), and they rated themselves poorly in swimsuits.

Latina women had and preferred more curvaceous bodies. About half wanted to have smaller bodies, $44 \%$ were satisfied with their busts; and $25 \%$ wanted to be two sizes larger; their BMI correlated with family, friends, and beach. This showed greater fat intolerance in Latina groups. Latina students wore conservative suits in front of family, friends, and beachside, and as their BMI increased, they wore less-revealing suits generally. The Latina women experienced fit problems and rated themselves average in swimsuits; $56 \%$ were satisfied with weight and waist.

Fashion and figure-conscious older women (Fashion Latinas and South Florida Moms) wanted to be 1-2 sizes smaller in body size but were mostly satisfied or wanted only one size larger for their busts. Their BMls affected their choices of most revealing suit. They were generally "satisfied with their appearance" and did not give themselves poor ratings. Some had and valued more curvaceous bodies. They were self-conscious in front of family, at the beach, and in private. And as their BMI increased, they wore more conservative suits.

The Black sample had higher BMIs and WCs, selected larger ideal figures, and desired to be only one size smaller in general. For the bust, about half wanted to be one size larger and the other half wanted to be one size smaller. They were more dissatisfied about their weight but chose larger real and ideal figures. They experienced problems with fit and rated themselves as average. As their BMI increased, they wore less-revealing suits in front of friends, at the beach, and in private. Although grouped together here as Black women,
Caribbean women differed slightly from African American women as most rated themselves higher on appearance and wore more-revealing suits in front of friends, beachside, and in private perhaps due to greater cultural positivity.

White students reported wanting to be 1-2 sizes smaller in body size, as well as larger in bust size; only $41 \%$ were satisfied with weight. They wore less-revealing suits in front of family but more revealing suits on the beach if they thought their appearance in a swimsuit was good. Those with higher BMI selected larger ideal body types than other samples.

Older women, both White and Latina (including Aqua-Aerobics women, North Florida Moms, and Department Store Latinas) had higher BMls and WCs. They selected larger ideal figures, both as perceived and ideal. They wore less-revealing suits in all situations, and were not satisfied with weight, appearance in a swimsuit, and their high WHRs. Many had curvaceous bodies and wanted their bodies to be $2-5$ sizes smaller.

A major finding of this study, and contrary to the literature (Webster \& Tiggemann, 2003, Paquette, 2004), was that body dissatisfaction did not dissipate with age but was maintained through the lifespan.

\section{Discussion}

The correlations showed that BMI, WC, and FRS were strongly associated. $\mathrm{BMI}$ affected the suits subjects choose to wear in certain situations. For the most part, larger BMI and WC were associated with a lower rating of appearance in swimsuits. Additionally, the larger the body figure selected, the more that lessrevealing suits were worn in certain situations, and the lower the rating of 
appearance in swimsuits. Participants wore more-revealing suits in each situation as their self-rating increased except for Competitors and Asians--the former because they rated their appearance high and could wear revealing suits (or not), and the latter who for cultural reasons wore more conservative suits.

Other physical measures were weakly associated with the Body FRS but had the same effect. Higher WHR made participants choose larger body figures as desirable, and higher WHR was associated with selecting smaller body figures, as well as less-revealing suits. Previous research (Singh, 1993; Singh \& Luis, 1995) demonstrated that because BMI was a ratio, it was possible for women with different weights and shapes to have similar scores. Older women chose larger ideal-body types because they found them more attractive. They grew up with an older ideal of beauty, the "36-24-36" hourglass figure and tended to select more curvaceous figures. Blacks and Latinas chose larger ideal shapes and considered larger bodies as healthier with general appearances mostly based on hair and clothing.

The "Difference between Real and Ideal Body FRS" showed participants' lack of satisfaction with their body shape. Participants with higher BMI had greater differences (i.e., chose smaller ideal figures than their real figures). The larger the BMI, the less satisfied participants were, except for the Competitors, who were satisfied with their body sizes. Perceived chest/bust size (Real Chest FRS) correlated less well than overall body shape. Black women were the exception and did not overestimate their body shape, being more fat-tolerant, they viewed themselves as attractive with many body shapes.
As participants selected a larger body figure than their perceived figure on the FRS, the Fit Difficulty increased, and their ratings in a swimsuit decreased. There were no correlations with Real Chest FRS and Difficulty of Fit, as the industry had already created large variations in sizes and shapes to accommodate women, including internal construction and tops with brassiere-type sizing to reduce fit problems.

The study showed the discrepancies between women's appearance in terms of how they looked, how they thought they looked, and how they would have liked to look. Women's dissatisfaction with body shape was manifested by rating their appearance in swimsuits, and how they felt about specific body characteristics (weight and waist). The machinations and agony that women have had in their quest to seek-out and purchase swimsuits that fit and that they "felt good in" was replete for the participants and was well-known and discussed throughout the swimwear industry.

Self-objectification has resulted in criticism of body-size and shape, and it has affected women's self-esteem and body satisfaction. In the subject data here, self-objectification affected women's behaviors in terms of places and locations where they would or would not show themselves; in less-to-more of the body revealed in public versus private; and in their social interactions with family, friends, and others. Bovet (2018, 2019) distinguished the "male gaze" on women's bodies related to fecundity and fertility potential but did not access mental abilities. The phenomenon of "self-objectification" linked to negative psychological consequences (Fredrickson \& Roberts, 1997; Hebl et al., 2004) showed that women's self-objectification viewed though a lens of swimsuits were perhaps 
proxies for the "male gaze" to evaluate women and girls' general appearance in terms of "sexiness" but it turned out, swimsuits reduced women's intellectual prowess as measured by poor results on mathematics' problems.

As for swimsuits themselves, an entire industry has attempted to produce products that appealed to customers' notions of glamour and attractiveness. Manufacturers also tried to ameliorate the displeasures of women's self-objectification to produce more attractive presentations of their bodies in public and private spaces, with new trends in fabrics, designs, shapes, and internal and external construction. Florida women, as well as others in pool/beach areas, attempted to deal with actual body-sizes and shapes in swimsuits. Although the results have not been as successful in improving women's self-esteem in recreational situations as hoped, the direction of these various aspects have been more positive than negative.

\section{Postscript}

Swimwear may initially have contributed to women's own self-objectification of their bodies, but in the $21^{\text {st }}$ century, women's control of their bodies and showing them in swimwear continues to change, mostly in better ways. Starting with Internet usage, on-line sales have included swimsuits in a multitude of sizes and shapes specifically allowing for greater body diversity. Currently, body positivity is stylish; fat is beginning to lose its stigma. The singer/entertainer Lizzo (Lieberman, 2021) whose BMl exceeds 40 (Extreme Obese) was a Vogue Magazine "cover-girl" (September 2020.) Plussize models are on runways and swimwear fashion shows demonstrate bodypositive images. Recently, the \#Fatkini movement featured women of many sizes taking selfies in swimsuits, then sharing and posting them on social media. Perhaps social media has allowed self-objectification "to morph" into women of many sizes and shapes shifting the negative "gaze" towards gaining "agency" by taking "selfies" while wearing swimsuits.

\section{References}

Abrams, L. S., \& Stormer, C. C. (2002) Sociocultural variations in the body image perceptions of urban adolescent females. Journal of Youth and Adolescence, 31(6): 443-450.

DOI:10.1023/a:1020211103936

Allan, J. D., Mayo, K., \& Michel, Y. (1993) Body size values of White and Black women. Research in Nursing \& Health, 16(5): 323-333.

DOI:10.1002/nur.4770160503

Anderson, D. A., Lundgren, J. D., Shapiro, J. R., \& Paulosky, C. A. (2003) Weight goals in a college-age population. Obesity Research, 11(2): 274-278. DOl:10.1038/oby.2003.4

Anderson-Fye, E.P. (2012) Anthropological perspectives on physical appearance and body image. In Cash, T. F. (Ed), Encyclopedia of Body Image and Human Appearance. (pp.15-21). Elsevier.

Barnett, H. I., Keel, P. K., \& Conoscenti, L. M. (2001) Body type preferences in Asian and Caucasian college students. Sex Roles, 45(11-12): 867-878. DOl:10.1023/A:1015600705749

Bhuiyan, A. R. (2003) Differences in body shape representations among young adults from a biracial (Black/White), semi-rural community: The Bogalusa Heart Study. American Journal of Epidemiology, 158(8): 792-797.

DOI:10.1093/aje/kwg218 
Bivans, Ann-Marie. (1991) Miss America: In Pursuit of the Crown. New York. MasterMedia

Borchert, J., \& Heinberg, L. (1996) Gender schema and gender role discrepancy as correlates of body image. The Journal of Psychology, 130(5): 547-559. DOl:10.1080/00223980.1996.9915021

Bovet, J. (2019) Evolutionary theories and men's preferences for women's waist-tohip ratio: Which hypotheses remain? A systematic review. Frontiers in Psychology. DOI:10.3389/fpsyg. 2019.01221

Bovet, J., M. Barkat-Defradas, V Durand, C. Faurie, and M. Raymond. (2018) Women's attractiveness is linked to expected age at menopause. Journal of Evolutionary Biology 31:229-238.

Byrd-Bredbenner, C., \& Murray, J. (2003) A Comparison of the anthropometric measurements of idealized female body images in media directed to men, women, and mixed gender audiences. Topics in Clinical Nutrition, 18(2): 117129. DOI:10.1097/00008486200304000-00008

Calogero, R.M. 2004. A test of objectification theory: The effect of the male gaze on appearance a in college women. Psychology of Women Quarterly. 28(1). 16-21.

Cash, T. F., Morrow, J. A., Hrabosky, J. I., \& Perry, A. A. (2004) How has body image changed? A cross-sectional investigation of college women and men from 1983 to 2001. Journal of Consulting and Clinical Psychology, 72(6): 1081-1089. DOI:10.1037/0022-006x.72.6.1081

Crawford, D., \& Campbell, K. (1999) Lay definitions of ideal weight and overweight. International Journal of Obesity, 23(7): 738-745. DOI:10.1038/sj.ijo.0800922
Cox, T. L., Zunker, C., Wingo, B., Thomas, D.-M., \& Ard, J. D. (2010) Body image and quality of life in a group of African American women. Social Indicators Research, 99(3): 531-540. DOl:10.1007/s11205-010-9602-y

Davis, C., Durnin, J. V., Dionne, M., \& Gurevich, M. (1994) The influence of body fat content and bone diameter measurements on body dissatisfaction in adult women. The International Journal of Eating Disorders, 15(3): 257-263. DOI: $10.1002 / 1098-$ 108X(199404)15:3<257::AIDEAT2260150309>3.0.CO;2-R

Deurenberg-Yap, M. and Deurenberg, P. (2003) BMl cut-off values for defining obesity among Asians. Nutrition Reviews. 61(12). 432-433.

Diekmann, J.M. (1997) Measuring body image. In M. Frank-Stromorg \& S.J. Olsen (Eds.), Instruments for Clinical Healthcare Research (3rd ed., pp.185203). Appleton and Lange.

Dittmar, H., \& Howard, S. (2004). Professional hazards? The impact of models' body size on advertising effectiveness and women's body-focused anxiety in professions that do and do not emphasize the cultural ideal of thinness. British Journal of Social Psychology, 43(4): 477-497. DOl:10.1348/0144666042565407

Doll, M., Ball, G. D. C., \& Willows, N. D. (2003) Rating of figures used for body image assessment varies depending on the method of figure presentation. International Journal of Eating Disorders, 35(1): 109-114. DOI:10.1002/eat.10233

Downs, D. M., James, S., \& Cowan, G. (2006) Body objectification, self-esteem, and relationship satisfaction: A comparison of exotic dancers and college 
women. Sex Roles, 54(11-12): 745752. DOI:10.1007/s11199-006-9042-y

Falconer, J. and Neville, H. 2000. African American college women's body image. Psychology of Women Quarterly 24: 236-243.

Fallon, A. (1990) Culture in the Mirror: Sociocultural Determinants of Body Image. Guilford Press.

Feingold, A., \& Mazzella, R. (1998) Gender differences in body image are increasing. Psychological Science, 9(3): 190195. DOI:10.1111/1467-9280.00036

Forestell, C. A., Humphrey, T. M., \& Stewart, S. H. (2004) Involvement of body weight and shape factors in ratings of attractiveness by women: A replication and extension of Tassinary and Hansen (1998). Personality and Individual Differences, 36(2): 295-305.

DOI:10.1016/s0191-8869(03)00085-0

Frank-Stromberg, M., Olsen, S. J. (2004) Instruments for Clinical Health-Care Research. London, England: Jones \& Bartlett.

Franzoi, S. L., \& Shields, S. A. (1984) The Body Esteem Scale: Multidimensional structure and sex differences in a college population. Journal of Personality Assessment, 48(2): 173-178. DOI:10.1207/s15327752jpa4802 12

Frederick, D. A., Daniels, E. A., Bates, M. E., \& Tylka, T. L. (2017) Exposure to thin-ideal media affect most, but not all, women: Results from the perceived effects of media exposure scale and open-ended responses. Body Image, 23: 188-205. DOI:10.1016/i.bodyim.2017.10.006

Fredrickson, B. L., Roberts, T.-A., Noll, S. M., Quinn, D. M., \& Twenge, J. M. (1998) "That swimsuit becomes you: Sex differences in self-objectification, restrained eating, and math performance. Journal of Personality and Social Psychology, 75(5): 1098-1098. DOI:10.1037/h0090332

Gardner, R. M., \& Brown, D. L. (2010) Body image assessment: A review of figural drawing scales. Personality and Individual Differences, 48(2): 107-111. DOI:10.1016/j.paid.2009.08.017

Gapinski, K. D., Brownell, K. D., \& LaFrance, M. (2003) Body objectification and "Fat Talk": Effects on emotion, motivation, and cognitive performance. Sex Roles, 48(9-10): 377-388.

DOI:10.1023/A:1023516209973

Gillen, M.M. and Lefkowitz, E.S. (2012) Gender and racial/ethnic differences in body image development among college students. Body Image. 9(1):126-130. 2011. DOl: 10.1016/j.bodyim.2011.09.004

Grabe, S., Ward, L. M., \& Hyde, J. S. (2008) The role of the media in body image concerns among women: A meta-analysis of experimental and correlational studies. Psychological Bulletin, 134(3): 460-476. DOI: 10.1037/0033$\underline{2909.134 .3 .460}$

Groesz, L. M., Levine, M. P., \& Murnen, S. K. (2001) The effect of experimental presentation of thin media images on body satisfaction: A meta-analytic review. International Journal of Eating Disorders, 31(1): 1-16. DOl: $\underline{10.1002 / \text { eat. } 10005}$

Haboush, A., Warren, C.S. \& Benuto, L. (2012) Beauty, ethnicity, and age: Does internalization of mainstream media ideals influence attitudes towards older adults? Sex Roles 66: 668-676. DOl: 10.1007/s11199-011-0102-6

Haimovitz, D., Lansky, L. M., \& O’Reilly, P. (1993) Fluctuations in body satisfaction

Spring, A., and V. McClain (2021) That Swimsuit Reveals You: Body Image and Bathing Suits of Florida Women. New Florida Journal of Anthropology 2(1):37-68. DOI:10.32473/nfja.v2i1.124046 
across situations. International Journal of Eating Disorders, 13(1): 77-84. DOI: 10.1002/1098-

$\overline{108 \times(199301) 13: 1<77:: \text { aid- }}$ eat2260130110>3.0.co;2-n

Harris, S. M. (1994) Racial differences in predictors of college women's body image attitudes. Women \& Health, 21(4): 89-104. DOI: 10.1300/j013v21n04 06

Hausenblas, H. A., Janelle, C. M., Gardner, R. E., \& Focht, B. C. (2004) Viewing physique plides: Affective responses of women at high and low drive for thinness. Journal of Social and Clinical Psychology, 23(1): 45-60. DOl:

$\underline{10.1521 / \text { iscp.23.1.45.26985 }}$

Hebl, M. R., King, E. B., \& Lin, J. (2004) The swimsuit becomes us all: Ethnicity, gender, and vulnerability to self-objectification. Personality and Social Psychology Bulletin, 30(10): 1322-1331. DOI: $\underline{10.1177 / 0146167204264052}$

Henriques, G. R., Calhoun, L. G., \& Cann, A. (1996) Ethnic differences in women's body satisfaction: An experimental investigation. The Journal of Social Psychology, 136(6): 689-697. DOI: $\underline{10.1080 / 00224545.1996 .9712245}$

Henss, R. (2000) Waist-to-hip ratio and female attractiveness. Evidence from photographic stimuli and methodological considerations. Personality and Individual Differences, 28(3), 501-513. DOl: $\underline{10.1016 / \mathrm{s} 0191-8869(99) 00115-4}$

Hermanussen, Michael, et al. (2019) The role of beliefs and perception on body size. Pediatric Endocrinol Review 16(3):284-30. DOl:10.17458/per.vol16.2019.hps.mr.26 achauersoiree

Jameca, W. F., \& Neville, H. A. (2000) African American college women's body image: An examination of body mass, African self-consciousness, and skin color satisfaction. Psychology of Women Quarterly, 24(3): 236-243. DOI: 10.1111/j.1471-6402.2000.tb00205.x

Jourard, S. M., \& Secord, P. F. (1954) Body size and body-cathexis. Journal of Consulting Psychology, 18(3): 184-184. DOI: $10.1037 / \mathrm{h} 0063192$

Kawamura, KY. (2012) Body image among Asian Americans. In Cash, T. F. (Ed), Encyclopedia of body Image and Human Appearance. (pp.95-102). Elsevier.

Katzmarzyk, P., \& Davis, C. (2001) Thinness and body shape of Playboy centerfolds from 1978 to 1998. International Journal of Obesity, 25(4): 590-592. DOI: $10.1038 /$ sj.ijo.0801571

Kjaerbye-Thygesen, A., Munk, C., Ottesen, B., \& Krüger Kjaer, S. (2004) Why do slim women consider themselves too heavy? A characterization of adult women considering their body weight as too heavy. International Journal of Eating Disorders, 35(3): 275-285. DOI: 10.1002/eat.10274

Knight, T. (2012) Body image among older adults. In Cash, T. F. (Ed), Encyclopedia of Body Image and Human Appearance. (pp.115-119). Elsevier.

Koff, E., \& Benavage, A. (1998) Breast size perception and satisfaction, body image, and psychological functioning in Caucasian and Asian American college women. Sex Roles, 38(7-8): 655-673.

DOl:10.1023/A:1018802928210

Lassek, W.D. \& Gaulin, S. (2016) What makes Jessica Rabbit sexy? Contrasting roles of waist and hip size. Evolutionary Psychology. DOI:10.1177/1474704916643459

Lassek, W.D. \& Gaulin, S. (2018) Do the low WHRs and BMls judged most

Spring, A., and V. McClain (2021) That Swimsuit Reveals You: Body Image and Bathing Suits of Florida Women. New Florida Journal of Anthropology 2(1):37-68. DOI:10.32473/nfja.v2i1.124046 
attractive indicate higher fertility? Evolutionary Psychology 14(2)

DOl:10.1177/1474704918800063

Lazuka, R. F., Wick, M. R., Keel, P. K., \& Harriger, J. A. (2020) Are we there yet? Progress in depicting diverse images of beauty in Instagram's Body Positivity Movement. Body Image, 34, 85-93. DOI:10.1016/j.bodyim.2020.05.001

Lieberman, L.S. \& Probart, C.K. (1992) Body weight: the normal, the ideal, the desirable. Antropol, 2: 279-295.

Lieberman, L.S. (2017) Nutritional anthropometry and body composition. In Chrzan \& Brett (eds.) Food Research: Nutritional Anthropology and Archaeological Methods. Berghahn Press: New York.

Lieberman, L.S. (2018) Obesity. In Callen (Ed.) International Encyclopedia of Anthropology. Wiley-Blackwell: Hoboken, NJ.

Lieberman, L.S. (2021) "Epigenetics, Body Weight and Bias" unpublished paper. April 20.

Liechty, T., Freeman, P. A., \& Zabriskie, R. B. (2006) Body Image and beliefs about appearance: Constraints on the leisure of college-age and middle-age women. Leisure Sciences, 28(4): 311-330. DOI:10.1080/01490400600745845

Leon, G. R. (1975). Personality, body image, and eating pattern changes in overweight persons after weight loss. Journal of Clinical Psychology, 31(4), 618623. https://doi.org/10.1002/10974679(197510)31:4<618::aidjclp2270310408>3.0.c0;2-t

Low, K. G., Charanasomboon, S., Brown, C., Hiltunen, G., Long, K., Reinhalter, K., \& Jones, H. (2003) Internalization of the thin ideal, weight and body image concerns. Social Behavior and
Personality: An International Journal, 31(1), 81-89.

DOI:10.2224/sbp.2003.31.1.81

Mazur, A. (1986) U.S. trends in feminine beauty and over-adaptation. Journal of Sex Research, 22(3), 281-303. DOI:10.1080/00224498609551309

McClure, S.M. (2012) Body image among African Americans. In Cash, T. F. (Ed), Encyclopedia of body Image and $\mathrm{Hu}$ man Appearance. (pp.89-94). Elsevier.

McComb, S.E. \& Mills, J.S. (2020) A systematic review on the effects of media disclaimers on young women's body image and mood. Body Image 32: 34-52.

McKinley, N. M. (2006) Longitudinal gender differences in objectified body consciousness and weight-related attitudes and behaviors: Cultural and developmental contexts in the transition from college. Sex Roles, 54(3-4): 159-173. DOI:10.1007/s11199-006-9335-1

McLaren, L., \& Kuh, D. (2004) Body dissatisfaction in midlife women. Journal of Women \& Aging, 16(1-2), 35-54. DOl:10.1300/j074v16n01 04

Molloy, B. (1998) Body image and self-esteem: A comparison of African-American and Caucasian women Sex Roles. 38:631-643.

Morris, A., Cooper, T., \& Cooper, P. J. (1989) The changing shape of female fashion models. International Journal of Eating Disorders, 8(5), 593-596.

DOl:10.1002/1098108x(198909)8:5<593::aideat2260080511>3.0.c0;2-h

Myers, P. N., \& Biocca, F. A. (1992) The elastic body image: The effect of television advertising and programming on body image distortions in young women. Journal of Communication, 42(3): 108-

Spring, A., and V. McClain (2021) That Swimsuit Reveals You: Body Image and Bathing Suits of Florida Women. New Florida Journal of Anthropology 2(1):37-68. DOI:10.32473/nfja.v2i1.124046 
133. DOI:10.1111/j.14602466.1992.tb00802.x

National Institute of Health. (2013) Body Mass Index, BMI Calculator, Healthy BMI. https://www.nhlbi.nih.gov/health/educational/lose wt/bmitools.htm

Neovius, M., Linné, Y., \& Rossner, S. (2004) BMI, waist-circumference and waist-hip-ratio as diagnostic tests for fatness in adolescents. International Journal of Obesity, 29(2): 163-169. DOI:10.1038/sj.ijo.0802867

Paquette, M.C., \& Raine, K. (2004) Sociocultural context of women's body image. Social Science \& Medicine, 59(5): 1047-1058.

DOI:10.1016/.j.socscimed.2003.12.016

Parker, S., Nichter, M., Nichter, M., Vuckovic, N., Sims, C., \& Ritenbaugh, C. (1995) Body image and weight concerns among African American and White adolescent females: Differences that make a difference. Human Organization, 54(2): 103-114.

DOl:10.17730/humo.54.2.06h663745q6 $\underline{50450}$

Peterson, M. (2004) Validity of the Body Mass Index Silhouette Matching Test. American Journal of Health Behavior, 28(5). DOI:10.5993/ajhb.28.5.6

Quinn, D. M., Kallen, R. W., Twenge, J. M., \& Fredrickson, B. L. (2006) The disruptive effect of self-objectification on performance. Psychology of Women Quarterly, 30(1): 59-64. DOl:10.1111/j.1471$\underline{6402.2006 .00262 . x}$

Roberts, A., Cash, T. F., Feingold, A., \& Johnson, B. T. (2006) Are Black-White differences in females' body dissatisfaction decreasing? A meta-analytic review. Journal of Consulting and Clinical Psychology, 74(6): 1121-1131. DOI:10.1037/0022-006x.74.6.1121
Roberts, T., Calogero, R. M., \& Gervais, S. J. (2018) Objectification Theory: Continuing contributions to feminist psychology. In C. B. Travis, et al. (Eds.), APA Handbooks in Psychology of Women: History, Theory, and Battlegrounds American Psychological Association. pp. 249-271. DOI:10.1037/0000059-013

Rosen, J. C., Srebnik, D., Saltzberg, E., \& Wendt, S. (1991) Development of a body image avoidance questionnaire. Psychological Assessment: A Journal of Consulting and Clinical Psychology, 3(1): 32-37. DOl:10.1037/10403590.3.1.32

Rozin, P., \& Fallon, A. (1988) Body image, attitudes to weight, and misperceptions of figure preferences of the opposite sex: A comparison of men and women in two generations. Journal of Abnormal Psychology, 97(3): 342-345. DOI:10.1037/0021-843x.97.3.342

Rozin, P., Trachtenberg, S., \& Cohen, A. B. (2001) Stability of body image and body image dissatisfaction in American college students over about the last 15 years. Appetite, 37(3); 245-248. DOI:10.1006/appe.2001.0426

Rucker, C. E., \& Cash, T. F. (1992) Body images, body-size perceptions, and eating behaviors among African American and White college women. International Journal of Eating Disorders, 12(3); $291-$ 299. DOI:10.1002/1098108x(199211)12:3<291::aideat2260120309>3.0.co;2-a

Sani, S. H. M. Eskandarnejad, and Z. Fathirezaie (2016) Body image, perceived physical fitness, physical activity, body mass index and age in women. Women's Health Bulletin 3(3)e31886. DOI:10.17795/whb-31886

Schlenker, J. A., Caron, S. L., \& Halteman, W. A. (1998) A feminist analysis of Seventeen Magazine: Content analysis from

Spring, A., and V. McClain (2021) That Swimsuit Reveals You: Body Image and Bathing Suits of Florida Women. New Florida Journal of Anthropology 2(1):37-68. DOI:10.32473/nfja.v2i1.124046 
1945 to 1995. Sex Roles, 38(1-2): 135149.

DOI:10.1023/A:1018720813673

Schooler, D., Lowery, L.S., \& Biesen, J.N. (2012) Body image among Hispanics/Latinos. In Cash, T. F. (Ed), Encyclopedia of Body Image and Human Appearance. (pp.108-113).Elsevier.

Schwartz, M. B., \& Brownell, K. D. (2004) Obesity and body image. Body Image, 1(1): 43-56. DOl:10.1016/S1740$\underline{1445(03) 00007-X}$

Secord, P. F., \& Jourard, S. M. (1953) The appraisal of body-cathexis: Body-cathexis and the self. Journal of Consulting Psychology, 17(5); 343-347. DOl:10.1037/h0060689SEyed

Silverstein, B., Perdue, L., Peterson, B., \& Kelly, E. (1986) The role of the mass media in promoting a thin standard of bodily attractiveness for women. Sex Roles, 14(9-10); 519-532. DOl:10.1007/bf00287452

Singh, D. (1993) Adaptive significance of female physical attractiveness: Role of waist-to-hip ratio. Journal of Personality and Social Psychology, 65(2); 293-307. DOI:10.1037/0022-3514.65.2.293

Singh, D., \& Luis, S. (1995) Ethnic and gender consensus for the effect of waist-tohip ratio on judgment of women's attractiveness. Human Nature, 6(1), 51-65. DOI:10.1007/bf02734135

Small, J. (2017) Women's "beach body" in Australian women's magazines. Annals of Tourism Research, 63; 23-33. DOI:10.1016/i.annals.2016.12.006

Stevens, M., \& Norwicki, E. M. (2003) Body mass index and mortality in Asian populations: implications for obesity cutpoints. Nutrition Reviews, 61(3); 104107. DOI:10.1301/nr.2003.marr.104-107
Swami, Viren, et al. (2020) The Breast Size Satisfaction Survey (BSSS): Breast size dissatisfaction and its antecedents and outcomes in women from 40 nations. Body Image 32:199-217.

Stunkard, A. J., Sorenson, T., \& Schulsinger, F. (1983) In S. S. Kety (Ed.), Genetics of Neurological and Psychiatric Disorders. pp 115-120. Raven.

Tantleff-Dunn, S., \& Thompson, J. K. (1998) Body image and appearance-related feedback: Recall, judgment, and affective response. Journal of Social and Clinical Psychology, 17(3): 319-340. DOI:10.1521/iscp.1998.17.3.319

Temerak, M. S. (2019) Bikini or Burkini? The role of swimwear and age as determinants of beach interaction with others. Tourism Management, 75; 269-283. DOI:10.1016/.tourman.2019.05.010

Thomas, M., \& DeCaro, J. A. (2017) Body Image Models among Low-income African American mothers and daughters in the Southeast United States. Medical Anthropology Quarterly, 32(2); 293-310. DOI:10.1111/maq.12390

Thompson, B. (1996) Multiracial feminist theorizing about eating problems: Refusing to rank oppressions. Eating Disorders, 4(2): 104114. DOl:10.1080/10640269608249178

Thompson, J. K., \& Altabe, M. N. (1991) Psychometric qualities of the figure rating scale. International Journal of Eating Disorders, 10(5); 615-619. DOl:10.1002/1098108x(199109)10:5<615::aideat2260100514>3.0.co;2-k

Thompson, J.K. \& Tantleff (1992) Female and male ratings of upper torso: Actual, ideal, and stereotypical conceptions. Journal of Social Behavior and Personality, 7(2): 345-354.

Spring, A., and V. McClain (2021) That Swimsuit Reveals You: Body Image and Bathing Suits of Florida Women. New Florida Journal of Anthropology 2(1):37-68. DOl:10.32473/nfja.v2i1.124046 
Thompson, J. K., \& Stice, E. (2001) Thinideal internalization: Mounting evidence for a new risk factor for body-image disturbance and eating pathology. Current Directions in Psychological Science, 10(5): 181-183. DOI:10.1111/1467$\underline{8721.00144}$

Thompson, J.K. \& Gardner, R. (2002) Measuring perceptual body image among adolescents and adults. In T. F. Cash \& T. Pruzinsky (Eds.), Body image: A Handbook of Theory Research, and Clinical Practice (pp. 135-141). Guilford Press.

Thompson J.K., \& Al, E. (2002) Exacting Beauty: Theory, Assessment and Treatment of Body Image Disturbance. American Psychological Association.

Thompson J.K., Patricia Van Den Berg, Roehrig, M., Guarda, A. S., \& Heinberg, L. J. (2004) The sociocultural attitudes towards appearance scale-3 (SATAQ3): Development and Validation. International Journal of Eating Disorders, 33: 293-304. DOI:10.1002/eat.10257

Tiggemann, M., \& Williamson, S. (2000) The effect of exercise on body satisfaction and self-esteem as a function of gender and age. Sex Roles, 43(1-2): 119-127. DOI:10.1023/A:1007095830095

Tiggemann, M., \& Lynch, J. E. (2001) Body image across the life span in adult women: The role of self-objectification. Developmental Psychology, 37(2): 243253. DOI:10.1037/0012-1649.37.2.243

Tiggemann, M. (2002) Media influences on body image development. In T. F. Cash \& T. Pruzinsky (Eds.), Body image: A Handbook of Theory Research, and Clinical Practice. (pp. 91-98). Guilford Press.

Tovée, M., Reinhardt, S., Emery, J., \& Cornelissen, P. (1998) Optimum body-mass index and maximum sexual attractiveness. The Lancet, 352(9127): 548. DOI:10.1016/s0140-6736(05)79257-6

Tovée, M. (2012). Anthropometry. In Cash, T. F. (Ed), Encyclopedia of Body Image and Human Appearance. (pp.108-113). Elsevier.

Warren, C. S., Gleaves, D. H., Cepeda-Benito, A., Fernandez, M. del C., \& Rodriguez-Ruiz, S. (2005) Ethnicity as a protective factor against internalization of a thin ideal and body dissatisfaction. International Journal of Eating Disorders, 37(3): 241-249. DOI:10.1002/eat.20102

Weaver, A. D., \& Byers, E. S. (2006) The Relationships among body image, body mass index, exercise, and sexual functioning in heterosexual women. Psychology of Women Quarterly, 30(4): 333339. DOl:10.1111/j.1471$\underline{6402.2006 .00308 . x}$

Webster, J., \& Tiggemann, M. (2003) The relationship between women's body satisfaction and self-image across the life span: The role of cognitive control. The Journal of Genetic Psychology, 164(2): 241-252. DOI:10.1080/00221320309597980

Wildes, J. E., Emery, R. E., \& Simons, A. D. (2001) The roles of ethnicity and culture in the development of eating disturbance and body dissatisfaction: A metaanalytic review. Clinical Psychology Review, 21(4): 521-551. DOl:10.1016/s0272-7358(99)00071-9

Wilson, J. M. B., Tripp, D. A., \& Boland, F. J. (2005) The relative contributions of waist-to-hip ratio and body mass index to judgements of attractiveness. Sexualities, Evolution \& Gender, 7(3): 245267. DOI:10.1080/14616660500238769

Zamani Sani, S. H., Eskandarnejad, M., \& Fathirezaie, Z. (2016) Body-image, perceived physical fitness, physical 
activity, body-mass index and age in women. Women's Health Bulletin, 3(3). DOl:10.17795/whb-31886

Zhu, S., Heymsfield, S. B., Toyoshima, H., Wang, Z., Pietrobelli, A., \& Heshka, S. (2005) Race-ethnicity-specific waist circumference cutoffs for identifying cardiovascular disease risk factors. The American Journal of Clinical Nutrition, 81(2): 409-415.

DOI:10.1093/ajen.81.2.409 